\title{
Glial $\beta$ II Spectrin Contributes to Paranode Formation and Maintenance
}

\author{
질 Keiichiro Susuki, ${ }^{1,3}$ Daniel R. Zollinger, ${ }^{1}$ Kae-Jiun Chang, ${ }^{1,2}$ Chuansheng Zhang, ${ }^{1}$ Claire Yu-Mei Huang, ${ }^{1}$ \\ [CChang-Ru Tsai, ${ }^{2}{ }^{\circledR}$ Mauricio R. Galiano, ${ }^{1}$ Yanhong Liu, ${ }^{1}$ Savannah D. Benusa, ${ }^{4}$ Leonid M. Yermakov, ${ }^{3}$ \\ Ryan B. Griggs, ${ }^{3}$ Jeffrey L. Dupree, ${ }^{4}$ and ${ }^{\oplus}$ Matthew N. Rasband ${ }^{1,2}$ \\ ${ }^{1}$ Department of Neuroscience, ${ }^{2}$ Program in Developmental Biology, Baylor College of Medicine, Houston, Texas 77030, ${ }^{3}$ Department of Neuroscience, Cell \\ Biology, and Physiology, Boonshoft School of Medicine, Wright State University, Dayton, Ohio 45435, and ${ }^{4}$ Department of Anatomy and Neurobiology, \\ Virginia Commonwealth University, Richmond, Virginia 23298
}

Action potential conduction along myelinated axons depends on high densities of voltage-gated $\mathrm{Na}^{+}$channels at the nodes of Ranvier. Flanking each node, paranodal junctions (paranodes) are formed between axons and Schwann cells in the peripheral nervous system (PNS) or oligodendrocytes in the CNS. Paranodal junctions contribute to both node assembly and maintenance. Despite their importance, the molecular mechanisms responsible for paranode assembly and maintenance remain poorly understood. $\beta$ II spectrin is expressed in diverse cells and is an essential part of the submembranous cytoskeleton. Here, we show that Schwann cell $\beta$ II spectrin is highly enriched at paranodes. To elucidate the roles of glial $\beta$ II spectrin, we generated mutant mice lacking $\beta$ II spectrin in myelinating glial cells by crossing mice with a floxed allele of Sptbn1 with Cnp-Cre mice, and analyzed both male and female mice. Juvenile (4 weeks) and middle-aged (60 weeks) mutant mice showed reduced grip strength and sciatic nerve conduction slowing, whereas no phenotype was observed between 8 and 24 weeks of age. Consistent with these findings, immunofluorescence microscopy revealed disorganized paranodes in the PNS and CNS of both postnatal day 13 and middle-aged mutant mice, but not in young adult mutant mice. Electron microscopy confirmed partial loss of transverse bands at the paranodal axoglial junction in the middle-aged mutant mice in both the PNS and CNS. These findings demonstrate that a spectrin-based cytoskeleton in myelinating glia contributes to formation and maintenance of paranodal junctions.

Key words: myelin; node of Ranvier; paranode; spectrin

Significance Statement

Myelinating glia form paranodal axoglial junctions that flank both sides of the nodes of Ranvier. These junctions contribute to node formation and maintenance and are essential for proper nervous system function. We found that a submembranous spectrin cytoskeleton is highly enriched at paranodes in Schwann cells. Ablation of $\beta$ II spectrin in myelinating glial cells disrupted the paranodal cell adhesion complex in both peripheral and CNSs, resulting in muscle weakness and sciatic nerve conduction slowing in juvenile and middle-aged mice. Our data show that a spectrin-based submembranous cytoskeleton in myelinating glia plays important roles in paranode formation and maintenance.

\section{Introduction}

Rapid action potential conduction along myelinated nerve fibers depends on high densities of voltage-gated $\mathrm{Na}^{+}$(Nav) channels

Received Dec. 27, 2017; revised April 24, 2018; accepted May 14, 2018.

Author contributions: K.S. and M.N.R. designed research; K.S., D.R.Z., K.-J.C., C.Z., C.Y.-M.H., C.-R.T., M.R.G., Y.L., S.D.B., L.M.Y., R.B.G., and J.L.D. performed research; K.S., J.L.D., and M.N.R. analyzed data; K.S. and M.N.R. wrote the paper.

This work was supported by the National Multiple Sclerosis Society and the National Institutes of Health (Grant NS044916). Ultrastructural imaging was conducted at the VCU Microscopy Facility, which is supported in part by the NIH NINDS Grant 5P30 NS047463. We thank Marlesa Godoy (Department of Neuroscience, Baylor College of Medicine), Debra Townley (Integrated Microscopy Core, Baylor College of Medicine), Domenica E. Drouet, Duc Van Minh Nguyen, Cameron L. Smith, and Dr. Yoshinori Otani (Department of Neuroscience, Cell Biology and Physiology, clustered at regularly spaced sites called nodes of Ranvier (Rasband and Peles, 2015). Nodal Nav channels dramatically increase the speed and significantly reduce the metabolic demands of action potential propagation along myelinated axons. Formation of

Wright State University) for technical assistance; and Mike Bottomley (Statistical Consulting Center, Wright State University) for assistance with the statistics.

The authors declare no competing financial interests.

Correspondence should be addressed to either of the following: Dr. Keiichiro Susuki, Department of Neuroscience, Cell Biology and Physiology, Boonshoft School of Medicine, Wright State University, 3640 Colonel Glenn Highway, Dayton, OH 45435, E-mail: keiichiro.susuki@wright.edu; or Dr. Matthew N. Rasband, Department of Neuroscience, Baylor College of Medicine, One Baylor Plaza, Houston, TX 77030, E-mail: rasband@bcm.edu. DOI:10.1523/JNEUROSCI.3647-17.2018

Copyright $\odot 2018$ the authors $\quad 0270-6474 / 18 / 386063-13 \$ 15.00 / 0$ 
nodal Nav channel clusters requires intimate interactions between axons and myelinating glial cells: Schwann cells in the peripheral nervous system (PNS) and oligodendrocytes in the CNS. At paranodes flanking both sides of the node, these glial cells form junctions with the axon via a cell adhesion complex consisting of glial neurofascin (NF) 155 and axonal contactinassociated protein (Caspr) and contactin (Bhat et al., 2001; Boyle et al., 2001; Pillai et al., 2009). Paranodes restrict the mobility of nodal proteins, thereby contributing to assembly and long-term maintenance of the nodal Nav channel complex (Rasband et al., 1999; Zonta et al., 2008; Feinberg et al., 2010; Susuki et al., 2013; Desmazieres et al., 2014; Amor et al., 2017; Taylor et al., 2017). Furthermore, paranodes restrict voltage-gated $\mathrm{K}^{+}$channels to juxtaparanodes beneath the myelin sheath (Bhat et al., 2001; Boyle et al., 2001; Pillai et al., 2009). Thus, paranodes are critical regulators of the distributions of ion channels along myelinated axons. However, the molecular mechanisms that form and maintain these junctions remain poorly understood.

Recent studies showed that spectrins and ankyrins are important for node formation (for review, see Susuki et al., 2016; Nelson and Jenkins, 2017). Spectrins are submembranous cytoskeletal proteins consisting of $\alpha$ and $\beta$ subunits. $\beta$ Spectrins bind to actin and stabilize membrane proteins through scaffolding proteins including ankyrins and 4.1 proteins. The cytoskeletal proteins $\alpha \mathrm{II}$ spectrin, $\beta \mathrm{II}$ spectrin (Garcia-Fresco et al., 2006; Ogawa et al., 2006), and protein 4.1B (Ohara et al., 2000; Brivio et al., 2017) are enriched at paranodes of myelinated axons. Two $\alpha \mathrm{II}$ spectrins and two $\beta$ II spectrins interact to form a tetramer, whereas protein 4.1B links $\beta$ II spectrin to Caspr (Ogawa et al., 2006; Brivio et al., 2017). Axonal $\alpha$ II spectrin and $\beta$ II spectrin are required for paranode-mediated clustering of nodal Nav channels and juxtaparanodal clustering of $\mathrm{K}^{+}$channels (Zhang et al., 2013; Amor et al., 2017; Brivio et al., 2017; Huang et al., 2017). These studies show axonal spectrin-based cytoskeletons regulate formation and maintenance of specialized domains along myelinated axons.

In contrast to axons, much less is known about the composition and function of cytoskeletal proteins in glia. We previously showed that $\alpha$ II spectrin and $\beta$ II spectrin are expressed in myelinating Schwann cells where they contribute to myelination (Voas et al., 2007; Susuki et al., 2011). Because myelin is a highly polarized structure with specialized membrane domains, we reasoned that glial spectrins may also contribute to the functions of myelinating glia. To test this idea, we generated mice lacking $\beta$ II spectrin in myelinating glia.

\section{Materials and Methods}

Animals. Generation of Sptbn $1^{f / f}$ mice (Galiano et al., 2012) and Advil$\mathrm{lin}^{\mathrm{Cre} /+}$ (Avil-Cre);Sptbn1 ${ }^{f / f}$ (Zhang et al., 2013) were previously described. The mice expressing Cre recombinase under the control of the 2', 3'-cyclic nucleotide phosphodiesterase (Cnp) promoter Cnp $\mathrm{Cre}^{++}$ (Cnp-Cre) were a generous gift from Dr. Klaus Nave (Max Planck Institute of Experimental Medicine, Department of Neurogenetics, Göttingen, Germany;Lappe-Siefke et al., 2003). Animals were housed at the Center for Laboratory Animal Care at Baylor College of Medicine and Laboratory Animal Resources at Wright State University. Toe grip strength was measured as previously described (Zhang et al., 2013). We analyzed both male and female mice. All animal procedures were approved by the Institutional Animal Care and Use Committee at Baylor College of Medicine and Wright State University Laboratory Animal Care and Use Committee, and conform to the United States Public Health Service Policy on Humane Care and Use of Laboratory Animals.

Oligodendrocyte culture. Primary oligodendrocyte cultures were established following the protocol previously described (Galiano et al., 2004).
Briefly, cerebral hemispheres from newborn rats were dissected out, dissociated in culture medium, and cells were plated in Petri dishes precoated with poly-L-lysine $100 \mu \mathrm{g} / \mathrm{ml}$. The cells were maintained in DMEM-Glutamax media (Invitrogen) supplemented with $10 \%$ fetal calf serum (FCS; Invitrogen) for $10 \mathrm{~d}$. Then, the progenitor glial cells were detached from the dish and seeded into a new Petri dish that was incubated at $37^{\circ} \mathrm{C}$ in a $5 \% \mathrm{CO}_{2}$ for $20 \mathrm{~min}$ to allow the attachment of mainly microglial cells, whereas the oligodendrocyte precursor cells (OPCs) remained in the suspension. This suspension was centrifuged, and the OPCs were suspended in DMEM supplemented with 10\% FCS, and seeded in new Petri dishes. Four hours later, the media was replaced by a chemically defined media [DMEM:F-12, 1:1 mixture plus $25 \mu \mathrm{g} / \mathrm{ml}$ insulin, $50 \mu \mathrm{g} / \mathrm{ml}$ transferrin, $30 \mathrm{~nm}$ sodium selenite, $4 \mathrm{mg} / \mathrm{ml}$ glucose, and penicillin $(100 \mathrm{IU} / \mathrm{ml})$, and streptomycin $(100 \mu \mathrm{g} / \mathrm{ml})]$.

Antibodies. The following primary antibodies were used: mouse monoclonal antibodies against $\beta$ II spectrin (BD Biosciences; RRID: AB_399853), $\alpha$ II spectrin (Millipore; MAB1622; RRID:AB_94295), AnkyrinG (AnkG; UC Davis/NIH NeuroMab Facility, N106/36; RRID: AB_10673030), Ankyrin B (NeuroMab, N105/17; RRID:AB_10674432), Kv1.2 (NeuroMab, K14/16; RRID:AB_2296313), pan-Nav channel (K58/35; RRID:AB_477552), myelin basic protein (MBP; BioLegend, SMI99; RRID:AB_2564741), rabbit polyclonal antibodies against $\beta$ II spectrin or $\alpha$ II spectrin (kindly provided by Dr. Michael C. Stankewich, Department of Pathology, Yale University, New Haven, CT), Caspr (RRID:AB_2572297), $\beta$ IV spectrin (RRID:AB_2315634), gliomedin (kindly provided by Dr. Elior Peles, Weizmann Institute of Science, Rehovot, Israel), dystrophin-related protein 2 (DRP2; kindly provided by Dr. Peter J. Brophy, Centre for Neuroscience Research, University of Edinburgh, Edinburgh, UK); chicken antibodies to NF (R\&D Systems, AF3235; RRID:AB_10890736). Secondary antibodies were from Jackson ImmunoResearch Laboratories.

Immunofluorescence studies. Immunostaining of the nerve sections, teased sciatic nerves, or oligodendrocytes in vitro was performed as described previously (Galiano et al., 2004; Schafer et al., 2004; Griggs et al., 2018) with minor modifications. Briefly, sciatic and optic nerves were rapidly dissected and immediately fixed in ice-cold $4 \%$ paraformaldehyde for $30 \mathrm{~min}$, cryoprotected in $20 \%$ sucrose overnight at $4^{\circ} \mathrm{C}$, cryosectioned, and mounted on coverslips. For teased fiber preparations, sciatic nerves were teased apart gently and spread on gelatin-coated coverslips, and air-dried. At different times of differentiation, the oligodendrocyte cultures were fixed using $4 \%$ paraformaldehyde, $\mathrm{pH}$ 7.2, for 20 min. Tissues or cells were blocked in $0.1 \mathrm{~m}$ phosphate buffer, $\mathrm{pH} 7.4$, containing $0.3 \%$ Triton X-100 and $10 \%$ goat serum (PBTGS), then primary antibodies were added overnight at $4^{\circ} \mathrm{C}$. Tissues or cells were washed with PBTGS, then secondary antibodies were added for $1 \mathrm{~h}$ at room temperature. The coverslips were then washed, air-dried, and mounted. Images were captured with a fluorescence microscope (Axio Observer Z1 with Apotome 2 fitted with AxioCam Mrm CCD camera; Carl Zeiss). Image analyses were performed using ZEN software from Carl Zeiss.

Western blotting. Protein extracts were collected at different times of differentiation in the oligodendrocyte cultures. Western blot analysis for spectrin expression was performed as previously described (Galiano et al., 2004) with minor modifications.

Electrophysiology. Motor nerve conduction studies in sciatic nerves were performed under general anesthesia with $2 \%$ isoflurane inhalation as described previously (Otani et al., 2017). In brief, sciatic nerve and its tibial branch were stimulated by needle electrodes inserted close to the nerve at ankle and sciatic notch. Supramaximal stimulations were used, and the evoked compound muscle action potentials were recorded from the plantar muscles through needle electrodes placed transversely over the muscle bellies in the sole of the foot. Motor nerve conduction velocity was measured between the ankle and the sciatic notch. Compound action potential recordings in optic nerves were performed as described previously (Zhang et al., 2013). In brief, optic nerves were dissected, placed in oxygenated Locke's solution containing $1 \mathrm{mg} / \mathrm{ml}$ glucose, and drawn into suction electrodes. Increasing current was applied until a supramaximal threshold was reached, and compound action potentials were recorded. Conduction velocities were calculated by dividing nerve length by com- 
pound action potential latency (the difference between stimulus onset and the time of maximal peak).

Morphological analyses. Sciatic nerves, optic nerves, and cervical spinal cords were prepared for analysis by transmission electron microscopy (TEM) as described previously (Marcus et al., 2006). In brief, mice were deeply anesthetized by intraperitoneal injection of ketamine $(80 \mathrm{mg} / \mathrm{kg})$ and xylazine $(16 \mathrm{mg} / \mathrm{kg})$, and transcardially perfused with $0.1 \mathrm{M}$ Millonig buffer containing $4 \%$ paraformaldehyde and $5 \%$ glutaraldehyde, $\mathrm{pH}$ 7.4. Following 2 weeks of postfixation in the same fixative, sciatic nerves, optic nerves, and cervical spinal cords were harvested and thoroughly rinsed in $0.1 \mathrm{M}$ cacodylate buffer. The samples were postfixed in $2 \%$

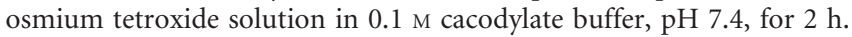
After washing in $0.1 \mathrm{M}$ cacodylate buffer, nerves were dehydrated through a graded ethanol series embedded in PolyBed 812 resin (PolySciences), and $90 \mathrm{~nm}$ sections were stained with uranyl acetate and lead citrate. Ultrathin sections were imaged using either JEOL JEM 1230 transmission electron microscope equipped with a Gatan Orius SC 1000 CCD camera or a JEOL JEM 1400 plus transmission electron microscope equipped with a Gatan One View 4K CCD camera. Quantification of myelin thickness by $g$-ratio (axon diameter/fiber diameter) measurement was performed as previously described (Marcus et al., 2006). The electron microscopy was performed in the Department of Anatomy and Neurobiology Microscopy Facility at Virginia Commonwealth University.

Experimental design and statistical analyses. Details of the experimental design are described in the Results or the figure legends along with the number of independent experiments or animals. Statistical analyses were performed using GraphPad Prism software. Student's $t$ test was used for comparison of two groups. For comparison of three groups, statistical significance was determined using a one-way ANOVA test followed by a Tukey's test as a post hoc analysis. Differences are considered significant at $p<0.05$. In graphs, results are given as mean \pm SEM.

\section{Results}

\section{Expression of $\boldsymbol{\beta}$ II spectrin in myelinating glia}

$\beta$ II and $\alpha$ II spectrin are enriched in the Schwann cell cytoplasmic Cajal bands located on the outer surface of the mature myelin sheaths in teased fiber preparation of sciatic nerves from wildtype (WT) mice (Fig. $1 A, B$ ). To determine whether $\beta$ II spectrin is expressed in CNS myelin, we analyzed cultured oligodendrocytes. Immunofluorescence microscopy showed that $\beta$ II spectrin is localized in processes of cultured oligodendrocytes, and is excluded from MBP-labeled membrane sheets (Fig. 1C). This localization pattern of $\beta \mathrm{II}$ spectrin is similar to that in the cytoplasmic bands of mature PNS myelin (Fig. 1A,B; Susuki et al., 2011). Immunoblotting further confirmed the expression of $\beta$ II spectrin in cultured oligodendrocytes (Fig. 1D). These results are consistent with previous studies showing expression of both $\beta$ II and $\alpha$ II spectrins in myelinating Schwann cells (Patzig et al., 2011), in myelin membranes isolated from human white matter and mouse brain (Gopalakrishnan et al., 2013), and in oligodendrocyte precursor cells and myelinating oligodendrocytes (Zhang et al., 2014). Previous coimmunoprecipitation data showed that $\beta I$ spectrin coimmunoprecipitates with $\alpha$ II spectrin from cultured rat Schwann cells (Susuki et al., 2011) and mouse brain homogenates (Ogawa et al., 2006). Together, these results demonstrate that $\beta$ II spectrin and $\alpha$ II spectrin form a complex and show a polarized distribution in myelinating glial cells in both the PNS and CNS.

To investigate the roles of glial spectrins in vivo, we generated mutant mice lacking $\beta$ II spectrin selectively in myelinating glial cells, because constitutive knock-out of $\beta$ II spectrin results in gastrointestinal, liver, neural, and heart defects, and the homozygous mutants die in utero (Tang et al., 2003), and because $\beta$ II spectrin is expressed in both axons (Ogawa et al., 2006; Zhang et al., 2013) and myelin (Susuki et al., 2011; Fig. 1). We crossed Sptbn1 ${ }^{f / f}$ mice (Galiano et al., 2012) with Cnp-Cre mice (Lappe-
Siefke et al., 2003); Cnp-Cre mice are a well established Cre driver line for conditional ablation of the target proteins in both myelinating Schwann cells and oligodendrocytes (Pillai et al., 2009; Chang et al., 2014). Hereafter, the conditional knock-out mice lacking glial $\beta I I$ spectrin will be referred to as Cnp-Cre;Sptbn $1^{f / f}$ or $c K O$ mice. As controls, we prepared Sptbn $1^{f / f}$ mice (referred to as WT) and Cnp-Cre;Sptbn1 $1^{f /+}$ (referred to as $c H e t$ ). We confirmed loss of $\beta$ II spectrin in myelinating Schwann cells in $c K O$ mouse sciatic nerves at 8 weeks of age (Fig. $1 A$ ). Immunostaining for $\alpha$ II spectrin and DRP2 in $c K O$ mice showed that Cajal bands were unaffected (Fig. $1 A, B$ ).

\section{Juvenile and middle-aged mice lacking glial $\beta$ II spectrin have impaired peripheral nerve conduction}

cKO mice did not show dramatic neurological symptoms. However, grip strength measurement revealed reduced muscle power in $c K O$ mice compared with $W T$ or $c H e t$ at 3 and 4 weeks after birth (Fig. 2A), that eventually resolved such that between 6 and 24 weeks of age $c K O$ mice did not show any weakness. Intriguingly, older $c K O$ mice (38 and 60 weeks old) showed reduced grip strength (Fig. 2A). To more directly analyze the function of myelinated axons, we measured motor nerve conduction velocity along sciatic nerves. Similar to the muscle weakness demonstrated by decreased grip strength (Fig. 2A), we observed significant nerve conduction slowing in $c K O$ mice at 4 and 6 weeks (Fig. $2 B$ ). Conduction velocities were indistinguishable between WT and $c K O$ sciatic nerves from 8 to 24 weeks, but were significantly slower in $c K O$ sciatic nerves at 38 and 60 weeks after birth. Two cKO mice survived up to 2 years, and their nerve conduction velocity was slower than controls. These findings demonstrate that loss of glial $\beta$ II spectrin causes mild muscle weakness and PNS nerve conduction slowing during development (until 6 weeks of age) and in middle-aged mice (60 weeks); surprisingly, young adult mice (8-24 weeks of age) have normal function.

To determine whether the functional changes in $c K O$ mice are due to changes in myelin ultrastructure, we analyzed cross sections of resin-embedded sciatic nerves. TEM analyses and $g$-ratio measurement showed compact myelin was mostly preserved in cKO sciatic nerves at postnatal day (P)13, 14 weeks, and 60 weeks of age (Fig. 3). Thus, it is unlikely that myelin defect alone is the major cause of reduced grip strength and sciatic nerve conduction slowing in juvenile or middle-aged $c K O$ mice.

\section{$\boldsymbol{\beta}$ II spectrin is at Schwann cell paranodes}

Because axonal $\beta$ II spectrin contributes to the molecular organization of nodes, paranodes, and juxtaparanodes (Zhang et al., 2013; Amor et al., 2017), we hypothesized that the Schwann cell $\beta$ II spectrin might also contribute to these structures. At first, we examined the localization of Schwann cell $\beta$ II spectrin at paranodes. Because spectrins are also expressed in axons including paranodes (Ogawa et al., 2006), it is difficult to distinguish between axonal and Schwann cell $\beta I I$ spectrin at the axon-Schwann cell interface in WT mice. Therefore, we took advantage of conditional knock-out mice lacking $\beta$ II spectrin in sensory axons (Zhang et al., 2013). In dorsal roots from WT mice, immunostaining of $\beta \mathrm{II}$ spectrin was seen along the axolemma in paranodes, juxtaparanodes, and internodes as well as at the myelin surface (Fig. 4). In dorsal roots from mutant mice lacking axonal $\beta$ II spectrin (Avil-Cre;Sptbn $1^{f / f}$ ), we found immunostaining of $\beta$ II spectrin at paranodes, whereas labeling in juxtaparanodes and internodes was completely abolished (Fig. 4). These results indicate that $\beta$ II spectrin is also highly enriched at paranodes in 


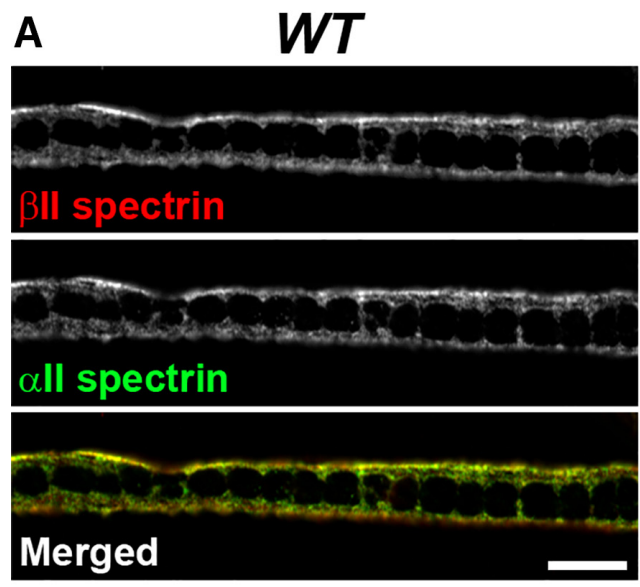

B
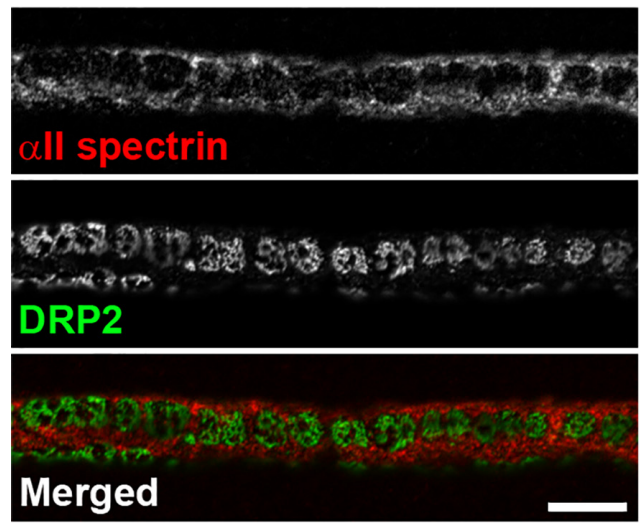

c Cultured OL

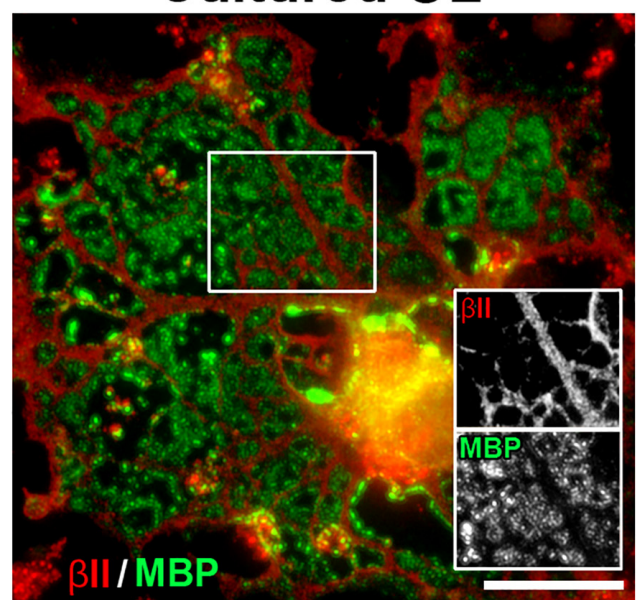

cKO

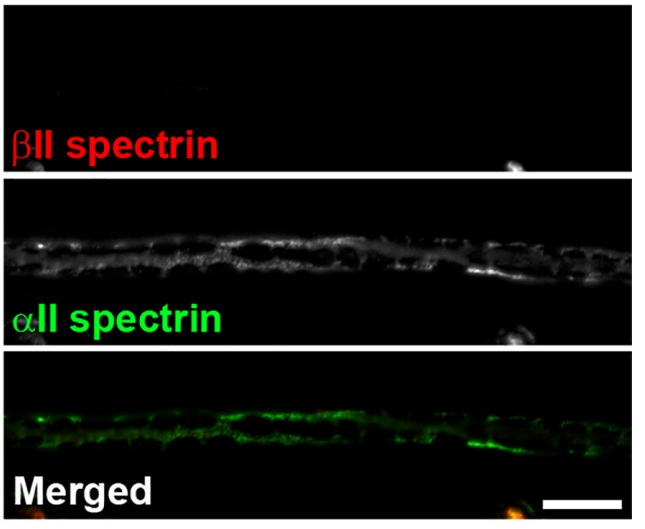

cKO

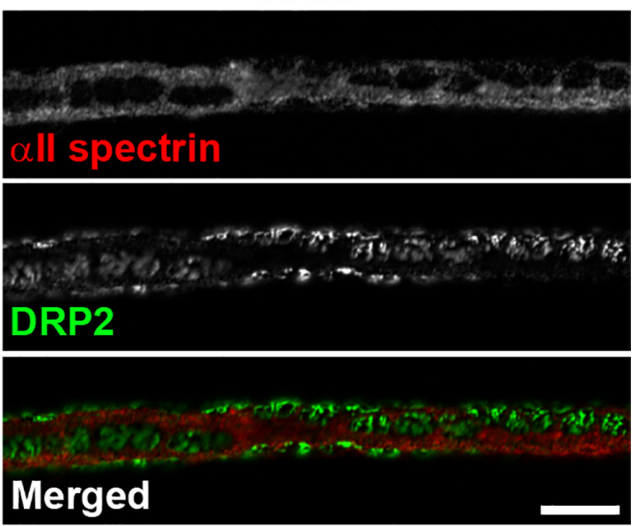

D

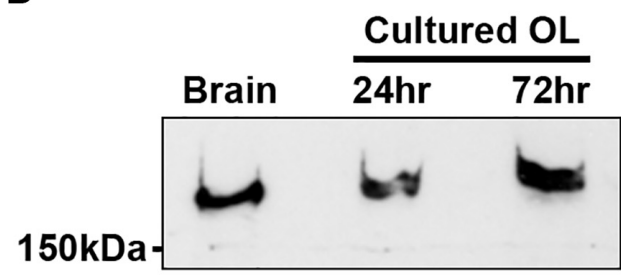

BII spectrin

Figure 1. $\quad \beta \| l$ and $\alpha \| l$ spectrin expression and localization in myelinating Schwann cells and oligodendrocytes. $A, B$, Teased fiber preparation of sciatic nerves from Sptbn $7^{f / f}$ mice $(W T$, left) or $\mathrm{Cnp}$-Cre;Sptbn $7^{f / f}$ mice (CKO, right) at 8 weeks of age. Nerves were labeled using antibodies against $\beta \|$ spectrin (red) and $\alpha \|$ spectrin ( $\boldsymbol{A}$, green), or against $\alpha \|$ spectrin (red) and DRP2 (B, green). Scale bars: $\boldsymbol{A}, \boldsymbol{B}, 10 \mu \mathrm{m}$. C, Cultured rat oligodendrocyte (0L) immunostained for $\beta \| \mathrm{l}$ spectrin (red) and MBP (green). Scale bar, $20 \mu \mathrm{m}$. D, Immunoblotting of brain homogenates and protein extracts derived from purified $0 \mathrm{~L}$ cultures of 24 and $72 \mathrm{~h}$ for $\beta \| \mathrm{l}$ spectrin.

Schwann cells. These findings support the idea that Schwann cell $\beta I I$ spectrin contributes to paranode organization and function.

$\boldsymbol{\beta}$ II spectrin-deficient Schwann cells cause disorganized nodes and paranodes during early development

Next, we examined clustering of nodal and paranodal proteins in sciatic nerves, because Schwann cell $\beta$ II spectrin is enriched at paranodes (Fig. 4), and paranodes play key roles for PNS node formation (Feinberg et al., 2010; Susuki et al., 2013; Amor et al., 2017). At P13, we occasionally found dispersed or reduced staining of Caspr and NF155 in $c K O$ sciatic nerves (Fig. 5A), suggesting disorganized paranodal architecture. Furthermore, clusters of nodal molecules such as NF186, AnkG, $\beta$ IV spectrin, or gliomedin were also frequently disorganized (Fig. $5 A-C$ ). In the PNS, glia-derived cell adhesion molecules such as gliomedin interact with NF186 at the nodal axolemma providing mechanisms for 
A

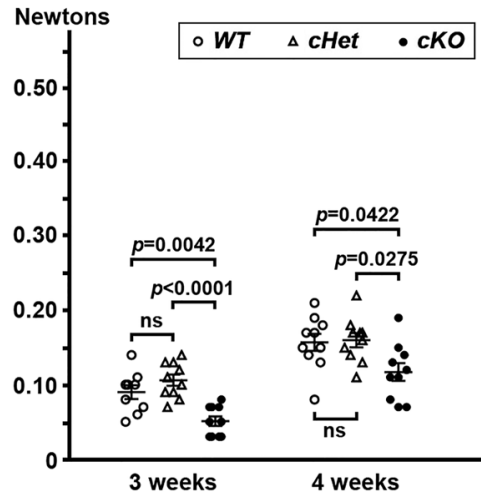

Grip strength

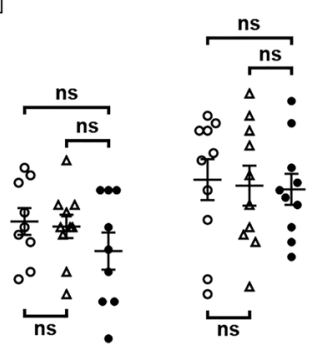

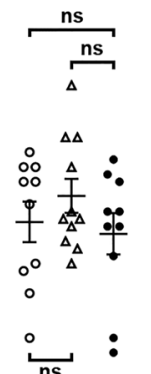

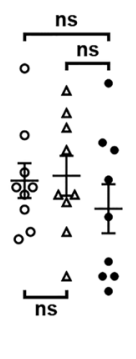

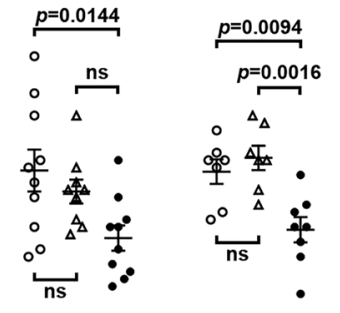

6 weeks

8 weeks

12 weeks

24 weeks

60 weeks

\section{B}

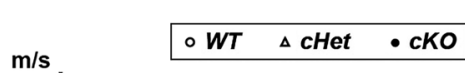
○WT $\triangle$ cHet $\bullet$ cKO

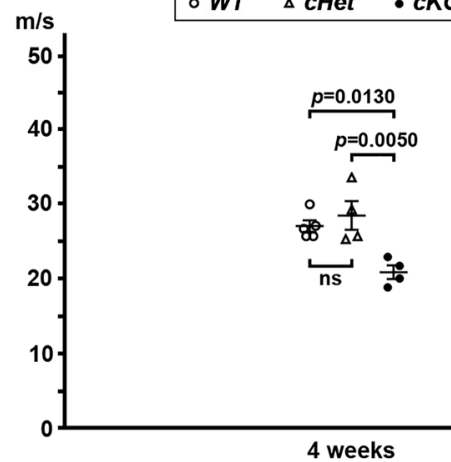

Motor nerve conduction velocity in sciatic nerves

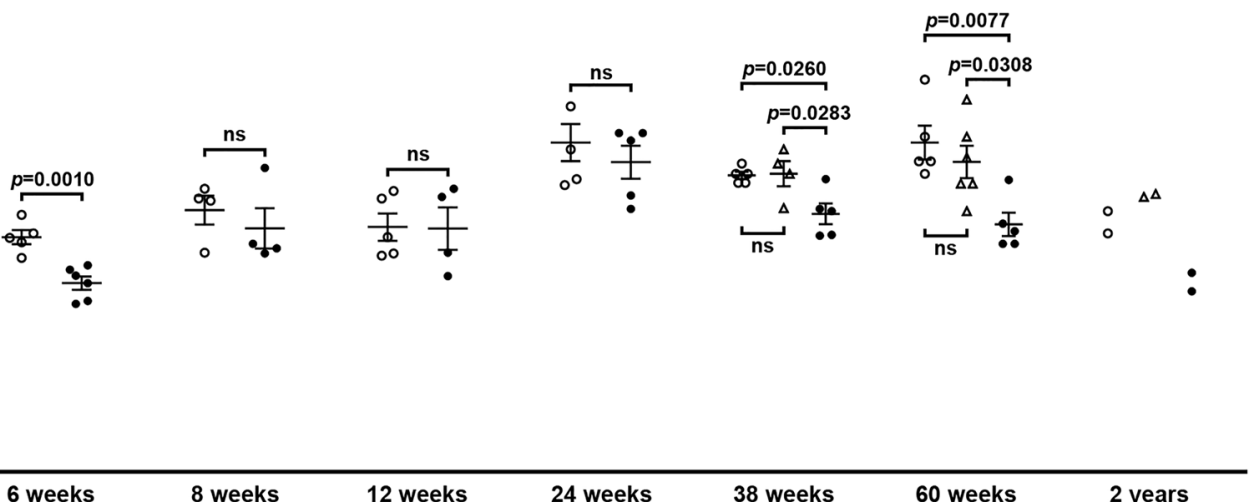

Figure 2. Phenotypes in mutant mice lacking $\beta \| l$ spectrin in myelinating glial cells. $\boldsymbol{A}$, Toe grip strength measurement. Grip strength in each mouse is plotted. $N=7-11$ mice in each group. $\boldsymbol{B}$, Motor nerve conduction velocity in sciatic nerves. Conduction velocity for each mouse is plotted. $N=4-6$ mice in each group. Differences of conduction velocity between $W T$ and $c K O$ are shown in

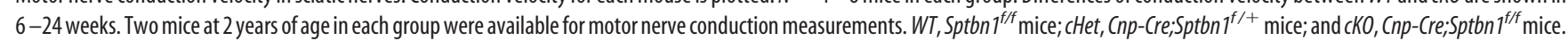

node formation (Eshed et al., 2005) and maintenance (Amor et al., 2014). The axonal scaffolding protein AnkG links NF186 to the cytoskeletal protein $\beta$ IV spectrin for stabilization of the nodal protein complex (Ho et al., 2014). The paranodal and nodal abnormalities described here were significantly more frequent in P13 cKO sciatic nerves compared with $W T$ or $c H e t$ (Fig. $5 D, E$ ). At 4 weeks of age when $c K O$ mice show both reduced grip strength and nerve conduction slowing (Fig. 2), disorganized paranodes were significantly more frequent in $c K O$ mice $(13.4 \pm 1.9 \%$, mean \pm SEM, $n=3$ mice) compared with $W T$ mice $(6.2 \pm 0.3 \%$, mean \pm SEM, $n=3$ mice; $p=0.0217$, Student's $t$ test). Disorganized nodes tended to be more frequent in $c K O$ mice $(5.9 \pm 1.3 \%$, mean \pm SEM, $n=3$ mice) compared with $W T$ mice $(1.7 \pm 0.9 \%$, mean \pm SEM, $n=3$ mice) at 4 weeks of age, although the difference did not reach statistical significance ( $p=0.0573$, Student's $t$ test). Consistent with normal grip strength and sciatic nerve conduction velocity in $c K O$ mice at 8-24 weeks of age (Fig. 2), nodes and paranodes appeared normal in 14-week-old $c K O$ sciatic nerves (Fig. $5 F, G$ ). In addition to the nodal and paranodal disorganization observed at P13, we also found abnormal clustering of $\beta \mathrm{IV}$ spectrin in internodal or paranodal regions of $c K O$ sciatic nerves (Fig. $5 H$ ). These aberrant $\beta$ IV spectrin clusters also colocalized with NF staining. Remarkably, in 14 weeks or older mice, these internodal $\beta \mathrm{IV}$ spectrin-containing clusters lacked NF staining (Fig. $5 H$ ). It is unclear how these aberrant $\beta$ IV spectrin clusters are formed, and their physiological consequence is unknown. Together, these results suggest that the loss of $\beta$ II spectrin in myelinating Schwann cells causes disorganized nodes and paranodes leading to transient nerve conduction slowing during early development.

\section{BII spectrin-deficient Schwann cells cause disorganized paranodes in middle-aged mice}

Next, we analyzed nodes and paranodes in sciatic nerves in middle-aged $c K O$ mice. We found that the clusters of paranodal molecules, both axonal Caspr and Schwann cell NF155, were disrupted in the sciatic nerves from $c K O$ mice at 60 weeks of age (Fig. 6A-D). Immunostaining of Caspr and NF155 was reduced at regions of the paranodes near the node, whereas the staining was preserved near juxtaparanodes. Even though the paranodal junctions were apparently disrupted, nodal clusters of NF186 and AnkG seemed to be intact, presumably due to preserved nodal extracellular matrix including gliomedin (Fig. 6A,B). Furthermore, disrupted paranodal junctions did not alter axonal $\beta I I$ spectrin at paranodes (Fig. 6D). Juxtaparanodal clusters including Kv1.2 were also preserved in association with residual NF155 in regions of the paranodes next to juxtaparanodes (Fig. 6C). Paranode disruption was significantly more frequent in $c K O$ sciatic nerves compared with WT or $c$ Het sciatic nerves (Fig. $6 E$ ). This pattern of paranodal abnormalities was rarely observed at 14 weeks: 0 of $400(0 \%)$ in WT; 6 of $400(1.5 \%)$ in cHet; and 3 of 400 $(0.75 \%)$ in $c K O$ (data were collected from 2 mice in each group). TEM further confirmed the paranodal disruption shown by immunofluorescence. In $c K O$ sciatic nerves at 60 weeks of age, we found partial loss of the transverse bands (Fig. $6 F$ ); transverse bands are a characteristic structural feature of paranodal axoglial 
A
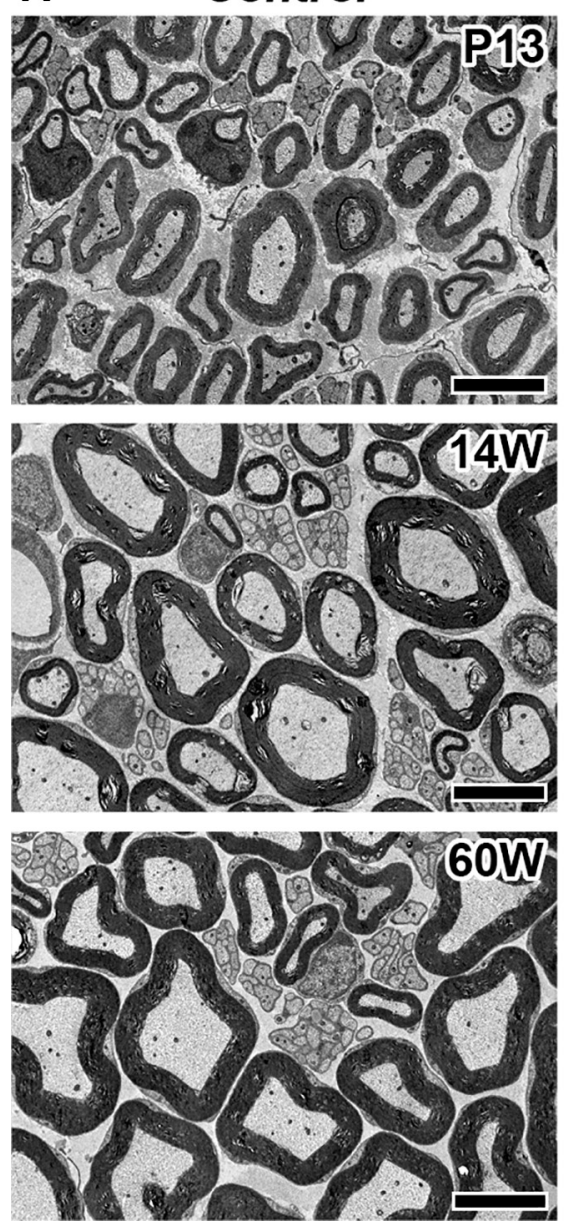

cKO
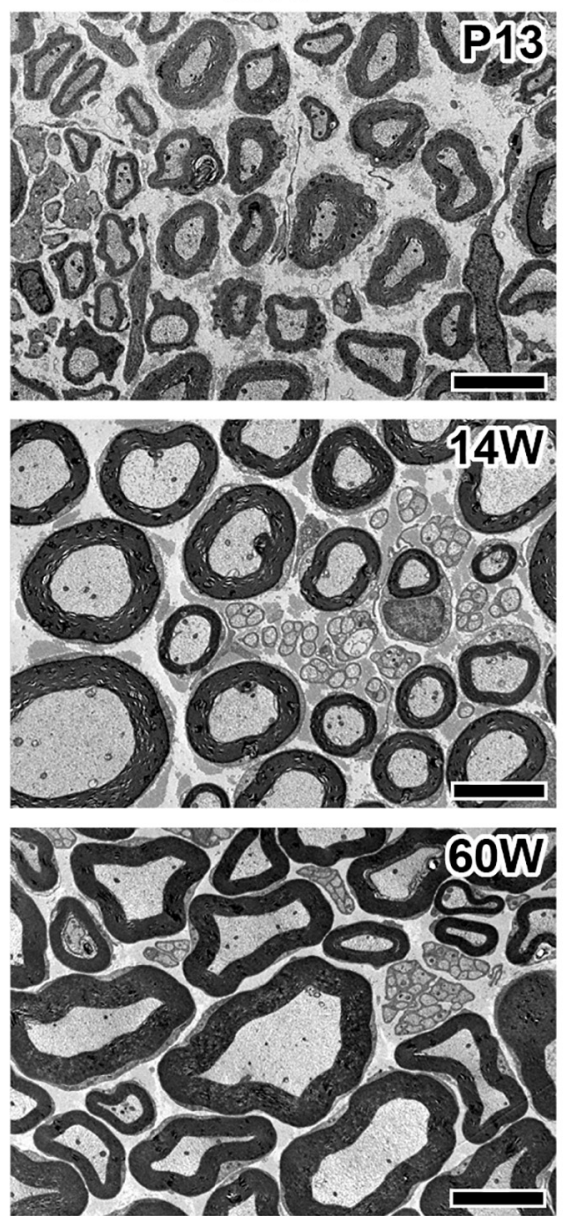

B Sciatic nerve g-ratio
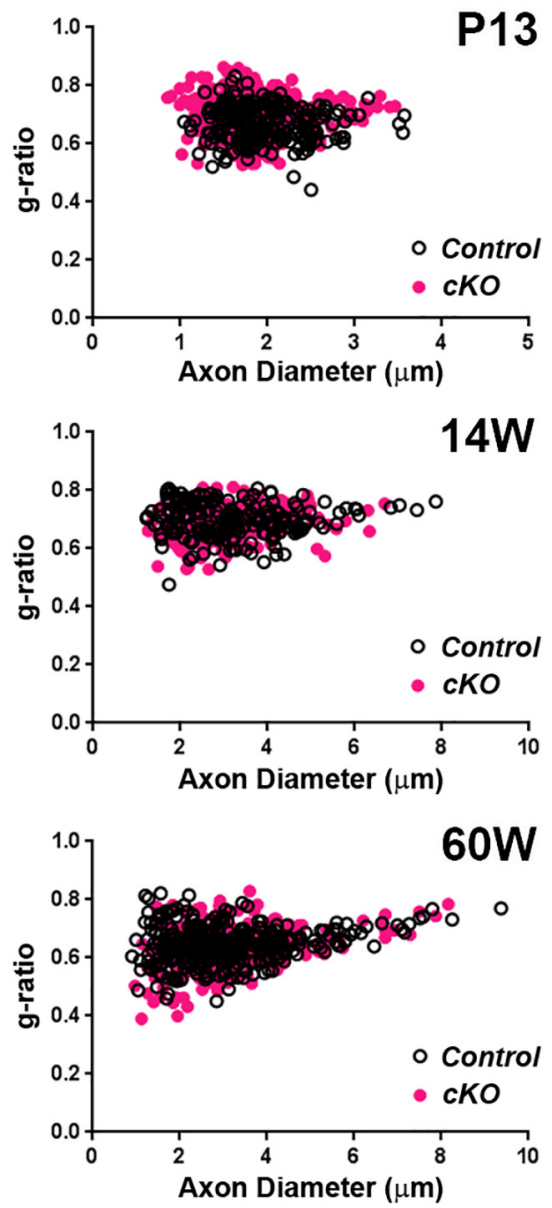

Figure 3. $\beta \| l l$ spectrin-deficient Schwann cell myelinated axons. $A$, Cross sections of sciatic nerves from Control (WT, Sptbn $7^{f / f}$ ); and cKO, Cnp-Cre;Sptbn $7^{f / f}$ mice at P13, 14 weeks, and 60 weeks of age. Scale bars, $5 \mu \mathrm{m} . \boldsymbol{B}$, Scatter plots of $g$-ratio $(y$-axis) in relation to axon diameter ( $x$-axis) of individual fiber in sciatic nerves. $g$-ratios: Control ( $0.6693 \pm 0.0617$, mean $\pm S D ; n=219$ axons) and $C K O(0.7131 \pm 0.0695$, mean $\pm S D ; n=316$ axons) at P13; Control ( $0.697 \pm 0.0578$, mean $\pm S D ; n=203$ axons) and $C K O(0.6871 \pm 0.0588$, mean \pm SD; $n=187$ axons) at 14 weeks of age; and Control ( $0.6447 \pm 0.0653$, mean $\pm S D ; n=315$ axons) and $c K O(0.6284 \pm 0.0698$, mean $\pm S D ; n=314$ axons) at 60 weeks of age. Data were collected from two control ( 1 WT and 1 (Het) and three $c K 0$ mice at P13; two control (WT) and two cKO mice at 14 weeks, and three control (WT) and three cK0 mice at 60 weeks of age. Approximately 100 axons were analyzed per mouse.
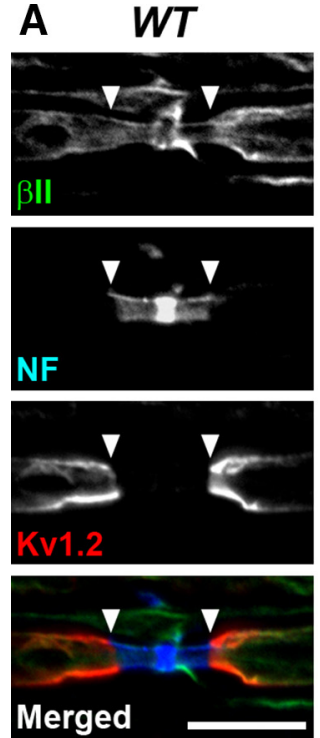

Axonal $\beta$ II $c K O$
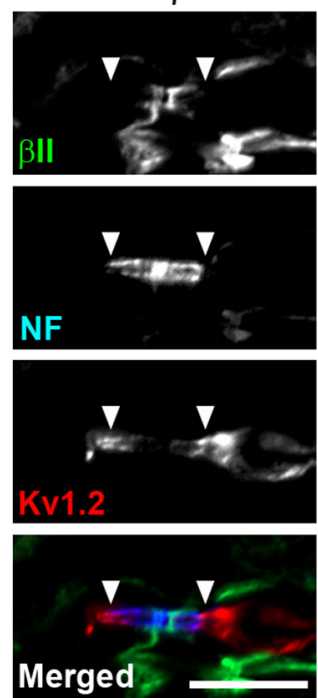
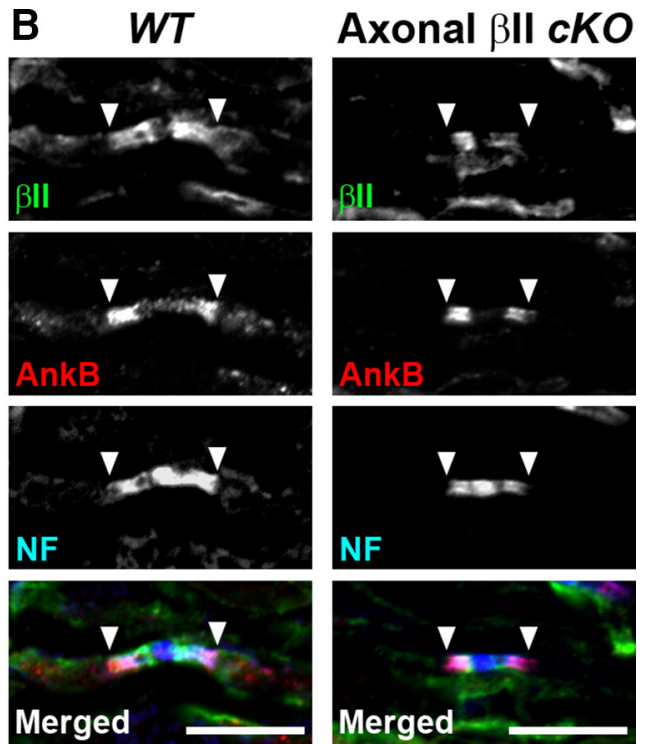

Figure 4. Schwann cell $\beta \| l$ spectrin is at paranodes. Dorsal roots from WT (Sptbn $7^{f / f}$ ) or mutant mice lacking $\beta \| l$ spectrin in sensory axons (axonal $\beta \| c K O$, Avil-Cre; Sptbn $7^{t / f}$ ) were immunostained using antibodies to $\beta \| l$ spectrin (green), NF (blue), and Kv1.2 ( $\boldsymbol{A}$, red), or antibodies to $\beta \| l$ spectrin (green), AnkyrinB (AnkB; red), and NF (B, blue). Arrowheads indicate the boundary between paranodes and juxtaparanodes. Scale bars, $10 \mu \mathrm{m}$. 
A P13 WT
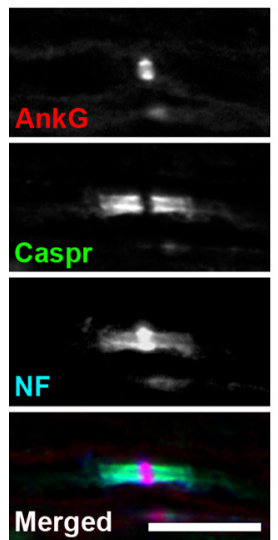

B P13 WT
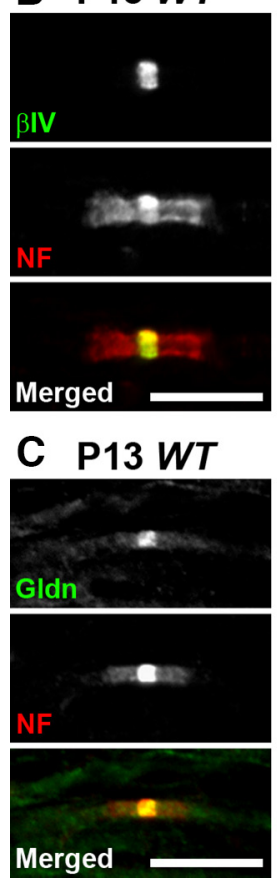

P13 cKO
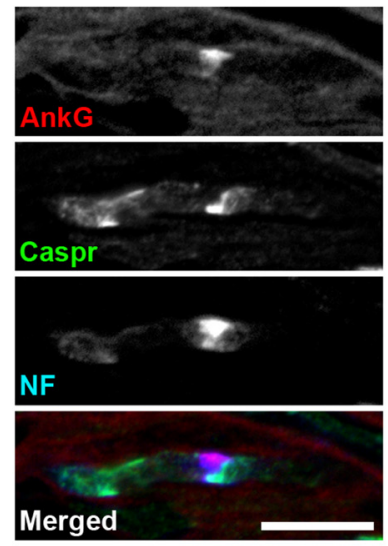

P13 cKO

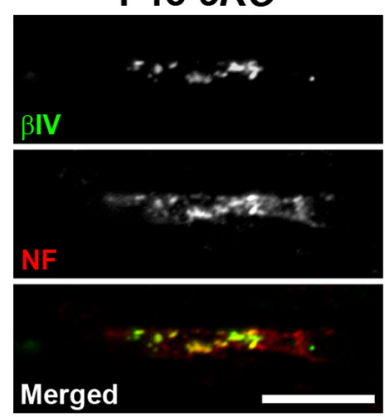

P13 cKO
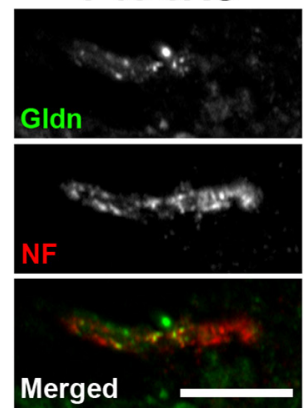

D P13 sciatic nerves Disorganized paranodes

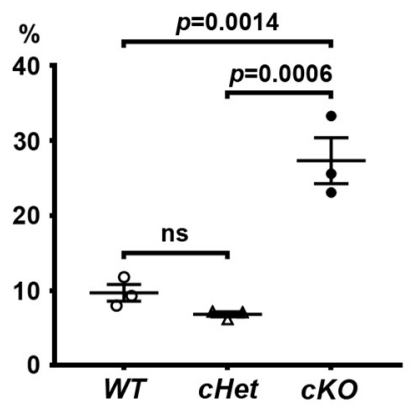

\section{E P13 sciatic nerves} Disorganized nodes

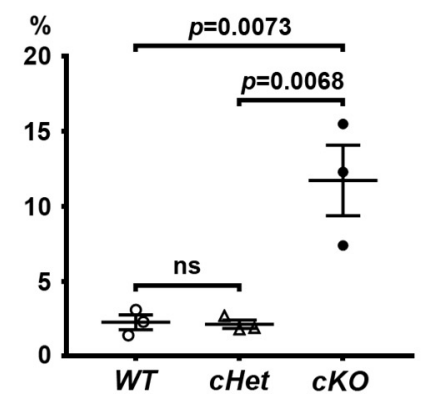

H

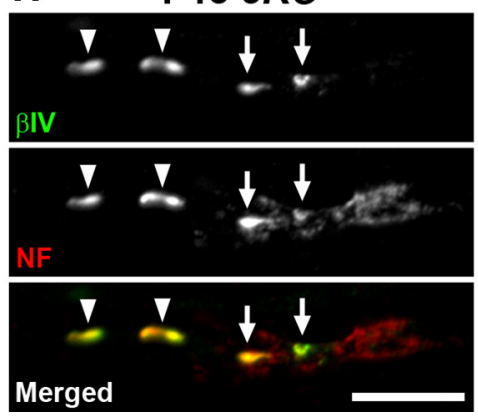

F $14 \mathrm{~W} W T$
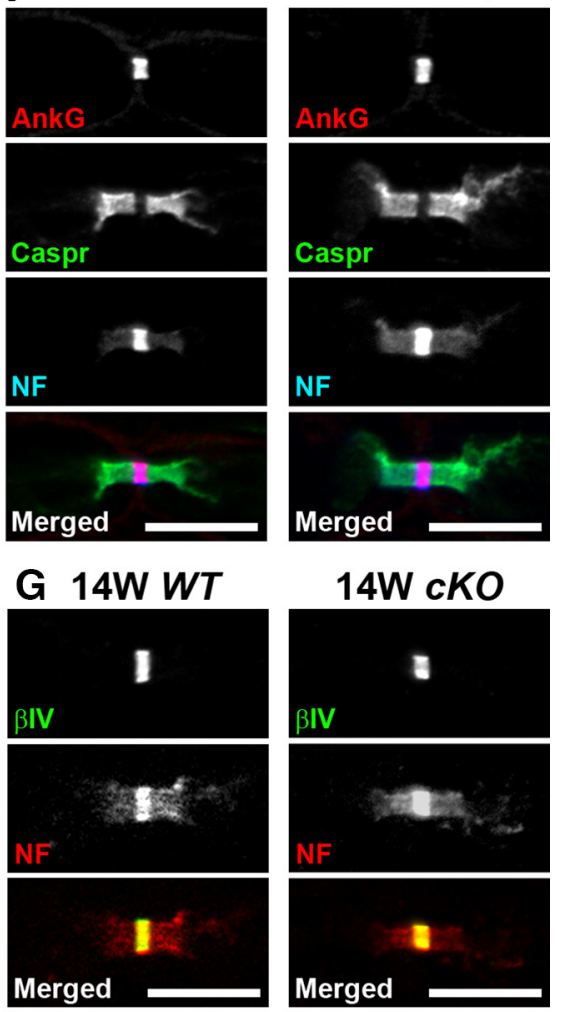

$14 \mathrm{~W}$ cKO

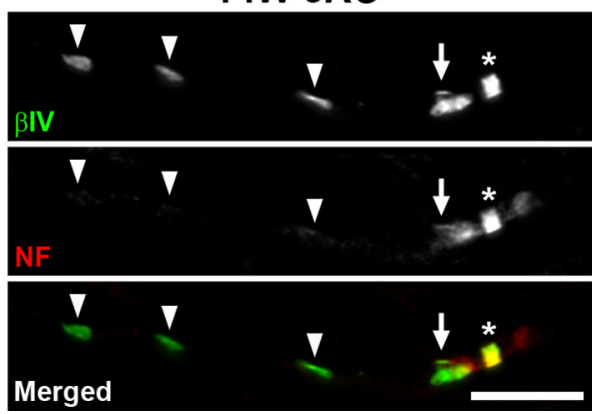

Figure 5. Altered paranode and node organization during early development in sciatic nerves lacking Schwann cell $\beta \| l$ spectrin. $\boldsymbol{A}-\boldsymbol{C}$, Sciatic nerve sections from P13 WT (Sptbn $1^{f / f}$ ) and $c K O$ (Cnp-Cre;Sptbn $7^{f / f}$ ) mice immunostained for AnkG (red), Caspr (green), and NF (A, blue), $\beta$ IV spectrin ( $\beta$ IV; green), and NF (B, red), or gliomedin (Gldn; green) and NF (C, red). Scale bars, $10 \mu m$.

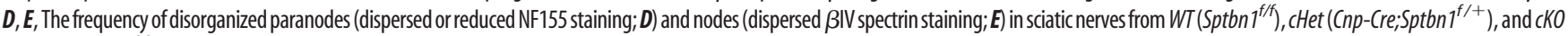
$\left(\mathrm{Cnp}\right.$-Cre;Sptbn $\left.1^{\mathrm{f} / \mathrm{f}}\right)$ mice at P13. Data were collected from three mice in each group. In each mouse, two sciatic nerve sections were analyzed, and $\sim 100$ paranodes and nodes were observed in each section. $\boldsymbol{F}, \mathbf{G}$, Sciatic nerve sections from WT and KO mice at 14 weeks of age immunostained for AnkG (red), Caspr (green), and NF (F, blue), or $\beta$ IV spectrin ( $\beta$ IV; green) and NF ( $\mathbf{G}$, red). Scale bars, $10 \mu \mathrm{m} . \boldsymbol{H}$, Sciatic nerve sections immunostained using antibodies against $\beta \mathrm{IV}$ spectrin (green) and NF (red). Ectopic $\beta$ IV spectrin clusters are observed at paranodes (arrows) or at internodes (arrowheads) in both P13 (left column) and 14 weeks (right column) cKO sciatic nerves. Asterisk indicates a node. Scale bars, $10 \mu \mathrm{m}$.

junctions. These results demonstrate that Schwann cell $\beta$ II spectrin helps maintain paranodal axoglial junctions in the PNS.

Oligodendrocyte $\beta$ II spectrin is required for timely assembly and continued maintenance of CNS paranodes

To determine whether $\beta$ II spectrin in myelinating oligodendrocytes contributes to the normal function of CNS myelinated axons, we measured conduction velocities of compound action potential propagation along CNS axons using an ex vivo preparation of the optic nerves. We found no significant difference in conduction velocities between $c K O$ and WT optic nerves at P17 or 23 weeks of age, whereas conduction velocity was significantly slower in middle-aged ( 60 weeks) $c K O$ mice compared with $c H e t$ mice (Fig. 7A). TEM analyses and $g$-ratio measurement showed compact myelin in optic nerves or spinal cords was indistinguish- able between control and $c K O$ mice at P13, 14 weeks, and 60 weeks of age (Fig. $7 \mathrm{~B}, C$ ). We occasionally found axons associated with thick myelin in 60 weeks $c K O$ optic nerves (Fig. $7 B$, asterisk), although myelin and axon integrity in most of fibers was comparable with control optic nerves. Thus, it is unlikely that optic nerve conduction slowing in middle-aged $c K O$ mice is caused by the defect of compact myelin alone.

Despite preserved nerve conduction velocity at P17 (Fig. 7A), when we analyzed nodal Nav channel clustering and the formation of paranodal junctions in P13 optic nerves, we found that Nav channel clusters were already formed in $c K O$ and WT mice, but Caspr labeling at paranodes was often dispersed or fragmented (Fig. 8A). Furthermore, we found Nav channel clusters without flanking Caspr labeling (Fig. $8 A$, arrowhead) were significantly more frequent in $\mathrm{cKO}$ optic nerves compared with $\mathrm{cHet}$ 
A $60 \mathrm{~W} W T$
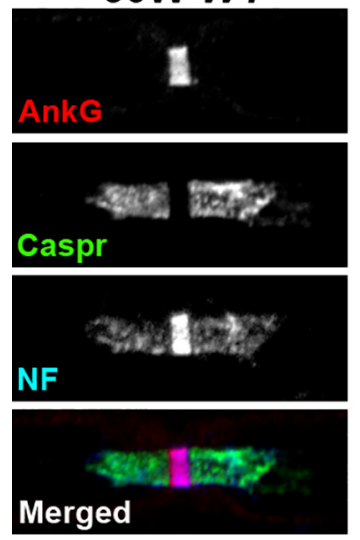

B $60 \mathrm{~W} W T$
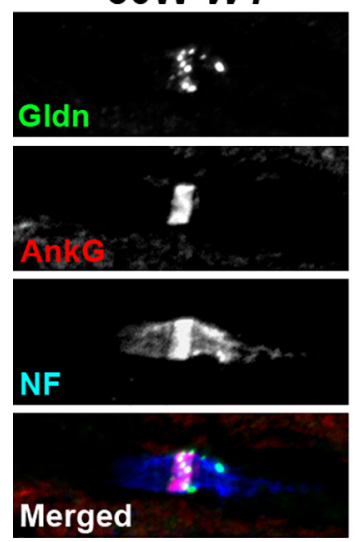

C $60 \mathrm{~W} W T$
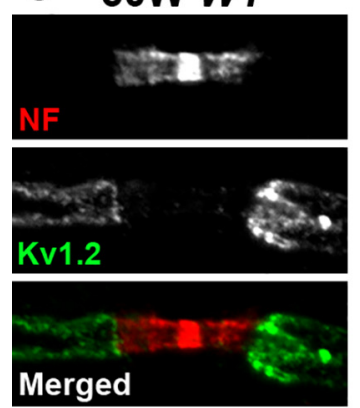

F

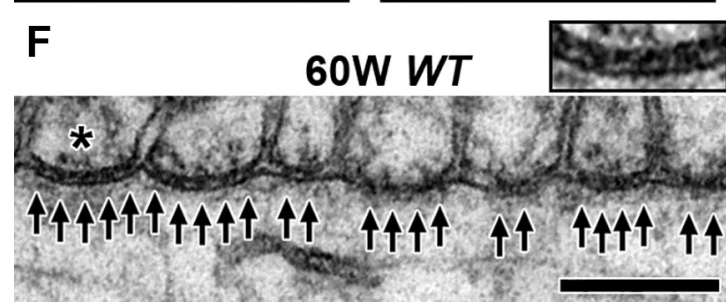

NF

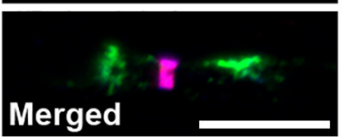

$60 \mathrm{~W}$ cKO
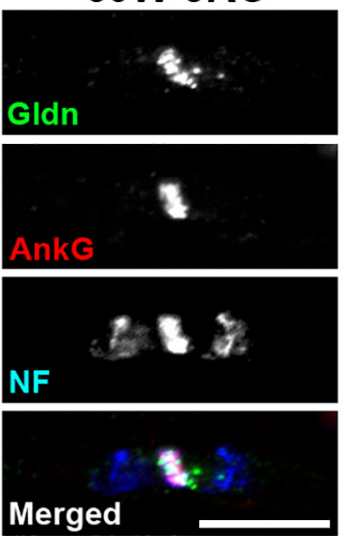

$60 \mathrm{~W}$ cKO
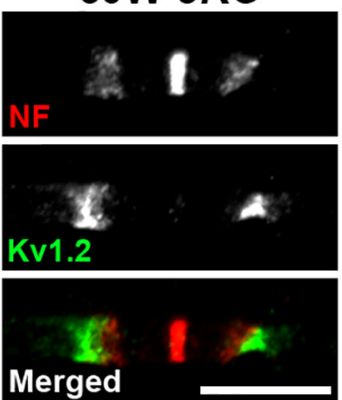

\section{Merged}

D $\quad 60 \mathrm{~W} W T$

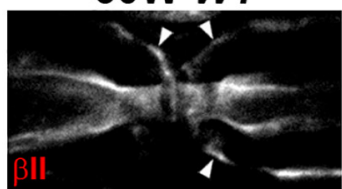

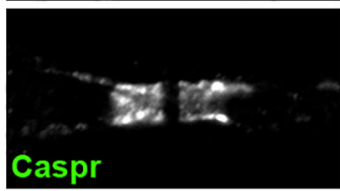
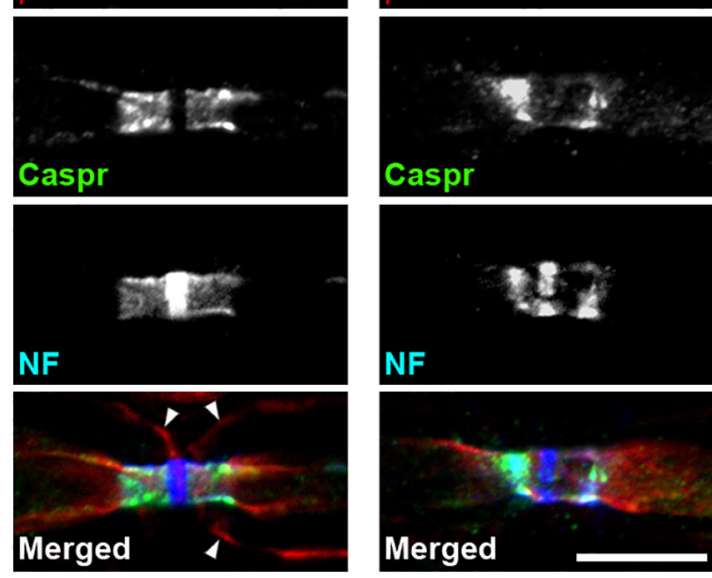

E 60 weeks sciatic nerves

Disrupted paranodes
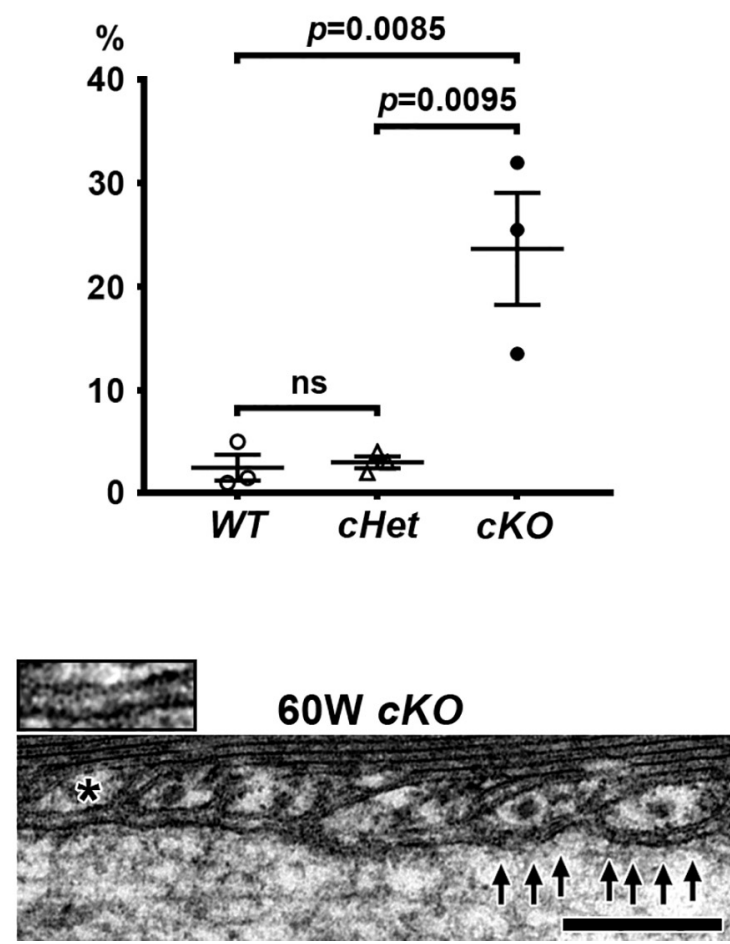

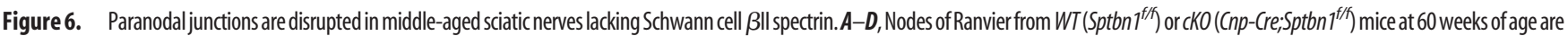
immunostained as indicated. Immunostaining of Caspr (green) and NF155 (blue) at paranodes is reduced in cKO nerves ( $\boldsymbol{A}-\boldsymbol{D})$. Nodal clusters of AnkG (A, $\boldsymbol{B}$, red), gliomedin (Gldn; $\boldsymbol{B}$, green), and NF186 (NF; $\boldsymbol{A}-\boldsymbol{D}$, blue) are preserved. Juxtaparanodal $\mathrm{Kv1.2} \mathrm{(green)} \mathrm{is} \mathrm{also} \mathrm{preserved} \mathrm{(C).} \mathrm{The} \mathrm{arrowheads} \mathrm{in} \boldsymbol{D}$ indicate $S c h w a n n$ cell $\beta \| l$ spectrin immunostaining near the outer surface of myelin sheath in $W T$ nerve, but this Schwann cell $\beta \| l$ spectrin staining is completely abolished in CKO nerve. Scale bars, $10 \mu \mathrm{m}$. E, Frequency of reduced paranodal Caspr and NF staining in sciatic nerves from WT (Sptbn $7^{\text {t/f) }}$, CHet (Cnp-Cre; Sptbn $\left.7^{f /+}\right)$, and $C K O\left(C n p-C r e ; S p t b n 7^{f / S}\right)$ mice at 60 weeks of age. $N=3$ mice in each group. Paranodes were judged as disrupted when significant gap (longer than $\left.1 \mu \mathrm{m}\right)$ was observed between paranodal Caspr/NF155 clusters and nodal AnkG/NF186 clusters $(\boldsymbol{A})$. In each mouse, two sciatic nerve sections were analyzed, and $\sim 100$ paranodes were observed in each section. $\boldsymbol{F}$, TEM images of paranodes in 60-week-old WT and cKO sciatic nerves. Arrows indicate transverse bands. The insets show enlarged images of axon-glial interface of paranodal lateral loops (asterisks). Scale bars, $0.2 \mu \mathrm{m}$.

optic nerves (Fig. 8B). Consistent with this observation, the frequency of mature nodes and paranodes (a Nav channel cluster flanked by Caspr staining on both sides) was significantly lower in cKO optic nerves compared with WT or cHet optic nerves (Fig.
$8 B)$. At 14 weeks of age, nodes and paranodes in $c K O$ optic nerves were mostly normal (Fig. $8 C$ ). These findings suggest that loss of $\beta$ II spectrin from myelinating oligodendrocytes delays paranode formation during early myelination, although the delay is not 


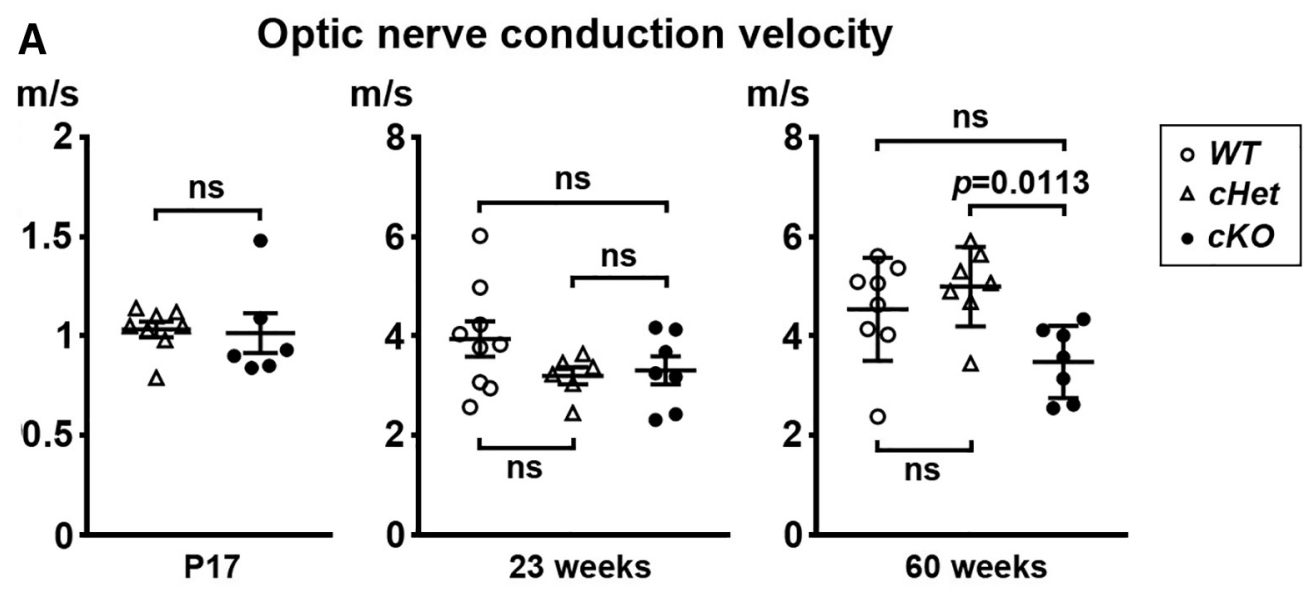

B
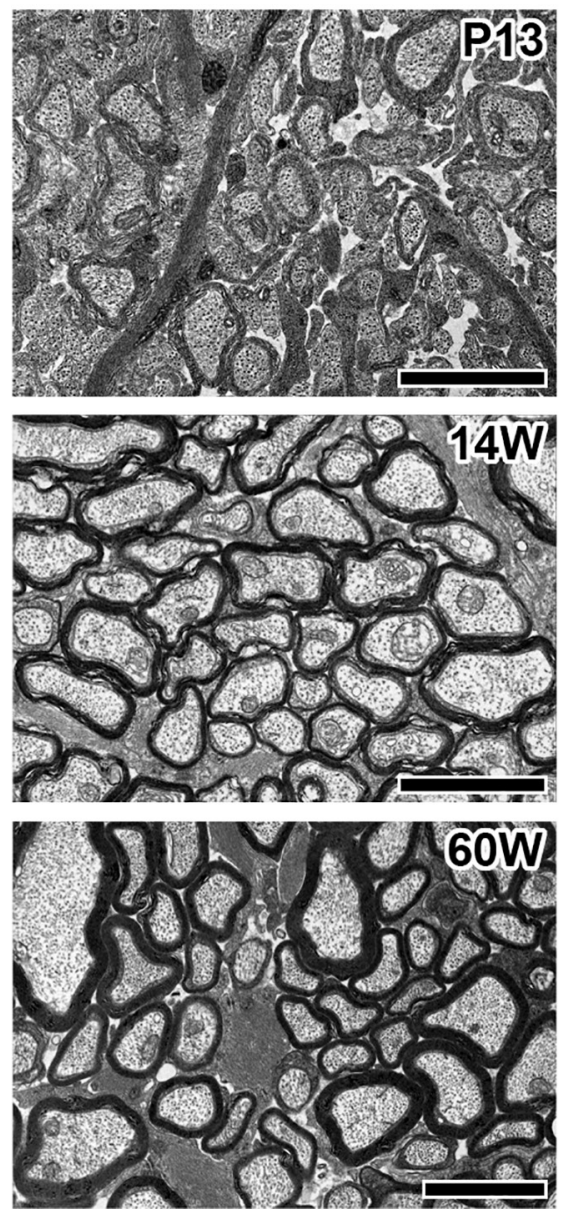
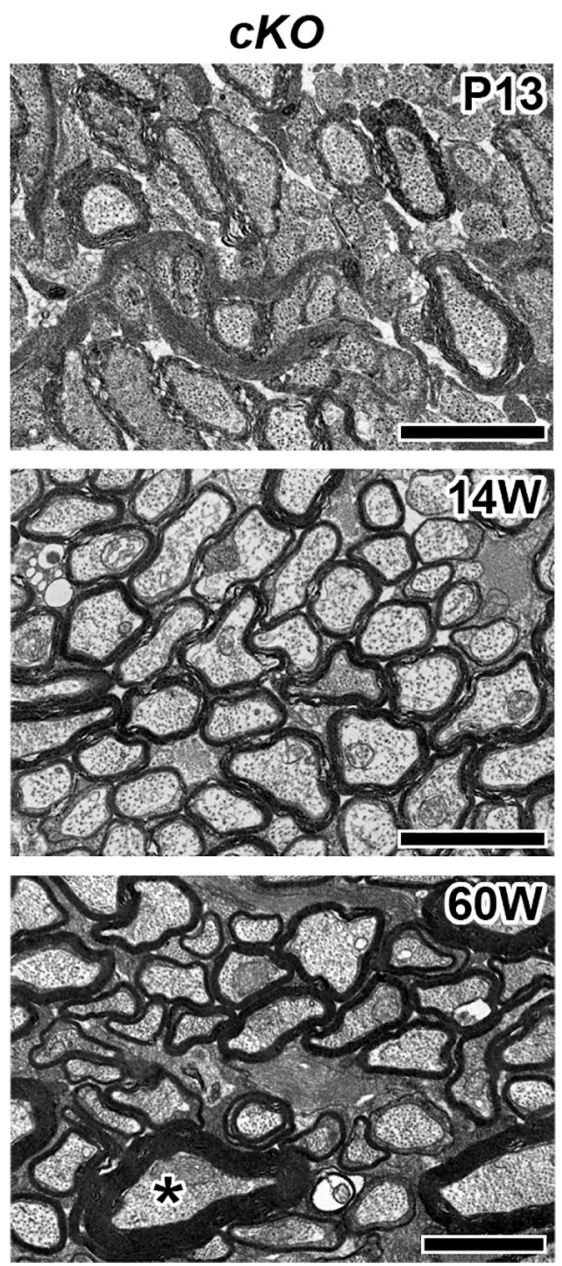

C Optic nerve g-ratio
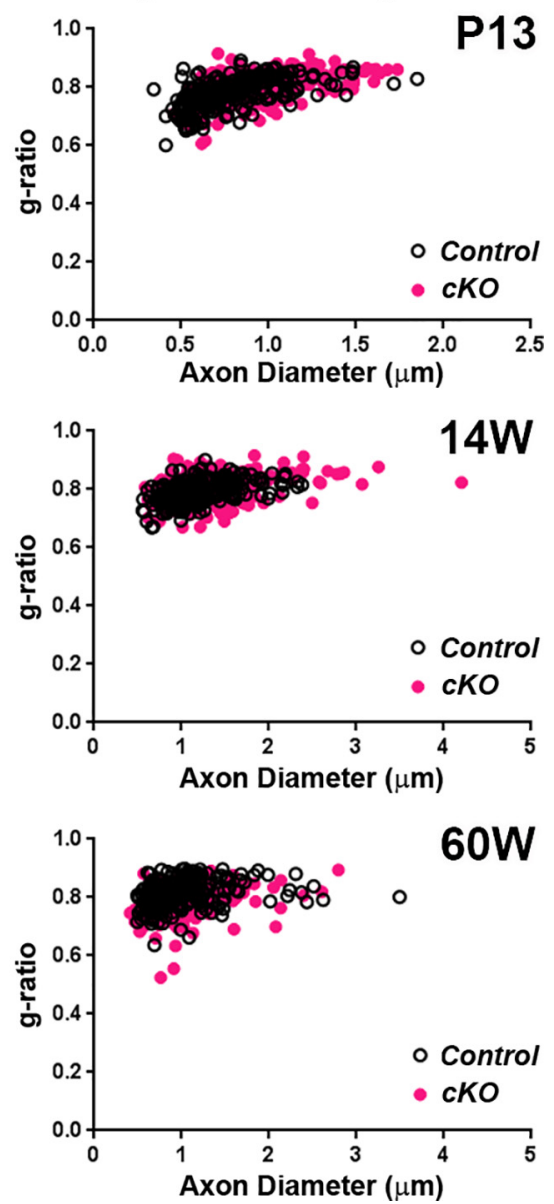

Figure 7. Nerve conduction and myelin morphology in optic nerves lacking oligodendrocyte $\beta \| l$ spectrin. $A$, Velocity of compound action potential propagation along optic nerves in ex vivo

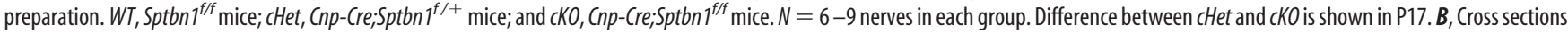
of optic nerves from Control (WT); and cKO mice at P13, 14 weeks, and 60 weeks of age. Asterisk indicates the axon associated with thick myelin. Scale bars, $2 \mu \mathrm{m}$. C, Scatter plots of $g$-ratio ( $y$-axis) in relation to axon diameter ( $x$-axis) of individual fiber in optic nerves. $g$-ratios: Control $(0.7792 \pm 0.0526$, mean $\pm S D, n=220$ axons) and $c K 0(0.7973 \pm 0.0462$, mean $\pm S D, n=310$ axons) at P13; Control ( $0.7906 \pm 0.0399$, mean $\pm S D, n=210$ axons) and $C K O(0.8038 \pm 0.0498$, mean $\pm S D, n=214$ axons) at 14 weeks of age; Control ( $0.8113 \pm 0.0474$, mean $\pm S D, n=214$ axons) and $c K O(0.7878 \pm 0.0535$, mean $\pm S D, n=217$ axons) at 60 weeks of age. Data were collected from two control ( 1 WT and 1 cHet) and two $K O$ mice at P13; two control (WT) and two $c K 0$ mice at 14 weeks, and two control ( 1 WT and $1 \mathrm{cHet}$ ) and two $\mathrm{CKO}$ mice at 60 weeks of age. Approximately 100 axons were analyzed per mouse.

severe enough to affect nerve conduction. Similar to PNS developmental myelination (Fig. 5), normal paranodes and nodes eventually form in the CNS despite the lack of glial $\beta$ II spectrin.

Next, we analyzed nodal and paranodal protein clusters in middle-aged $c K O$ mouse optic nerves by immunofluorescence. At
60 weeks of age, we found that paranodes were disorganized and Kv1.2 staining frequently overlapped with paranodal Caspr and NF155 immunoreactivity (Fig. 9A). This observation revealed a compromised paranodal diffusion barrier due to loss of $\beta$ II spectrin. Furthermore, nodal gaps were abnormally elongated in $c \mathrm{KO}$ optic 

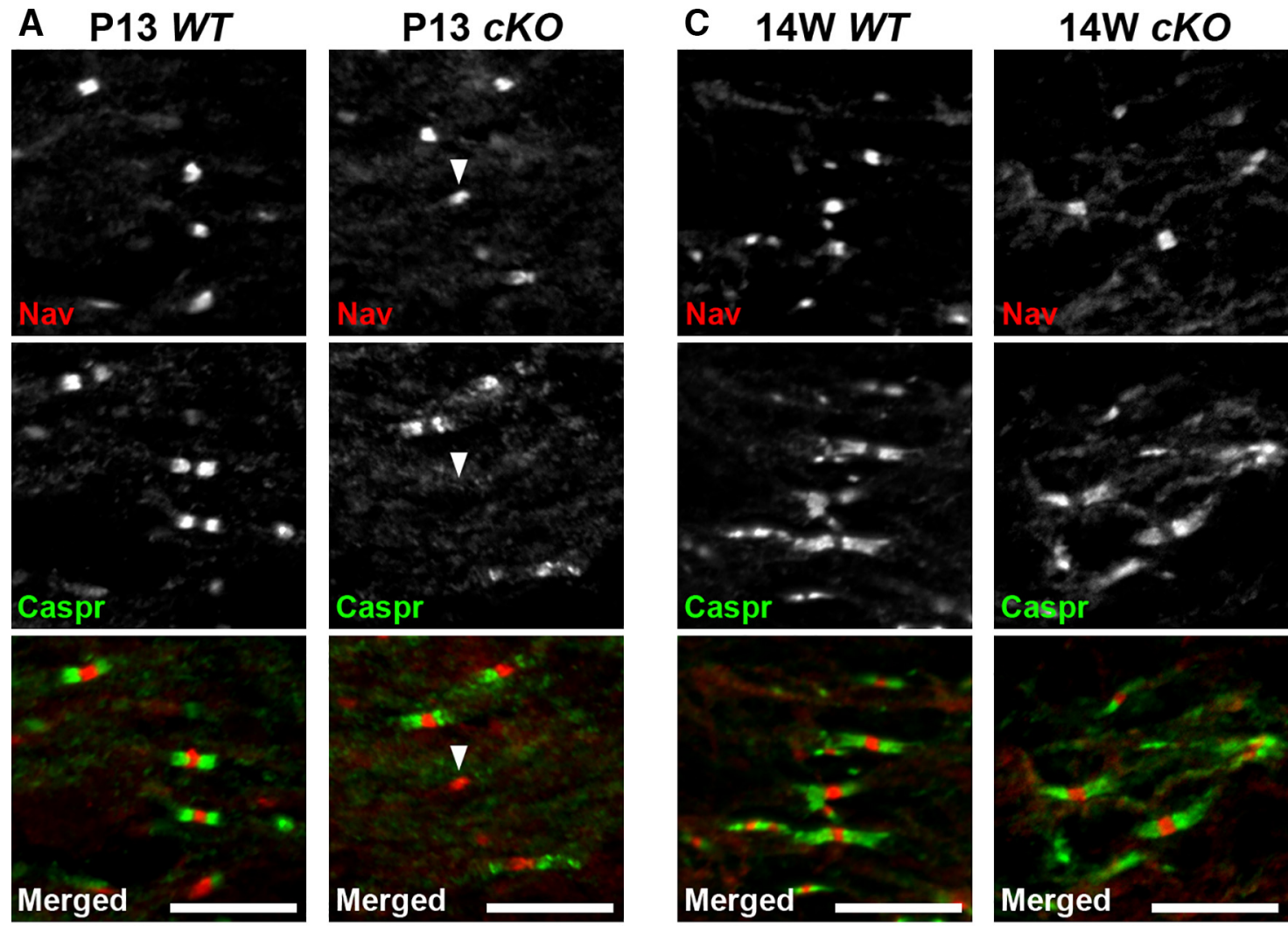

B

\section{Nav/Caspr labeled sites in P13 Optic nerves}

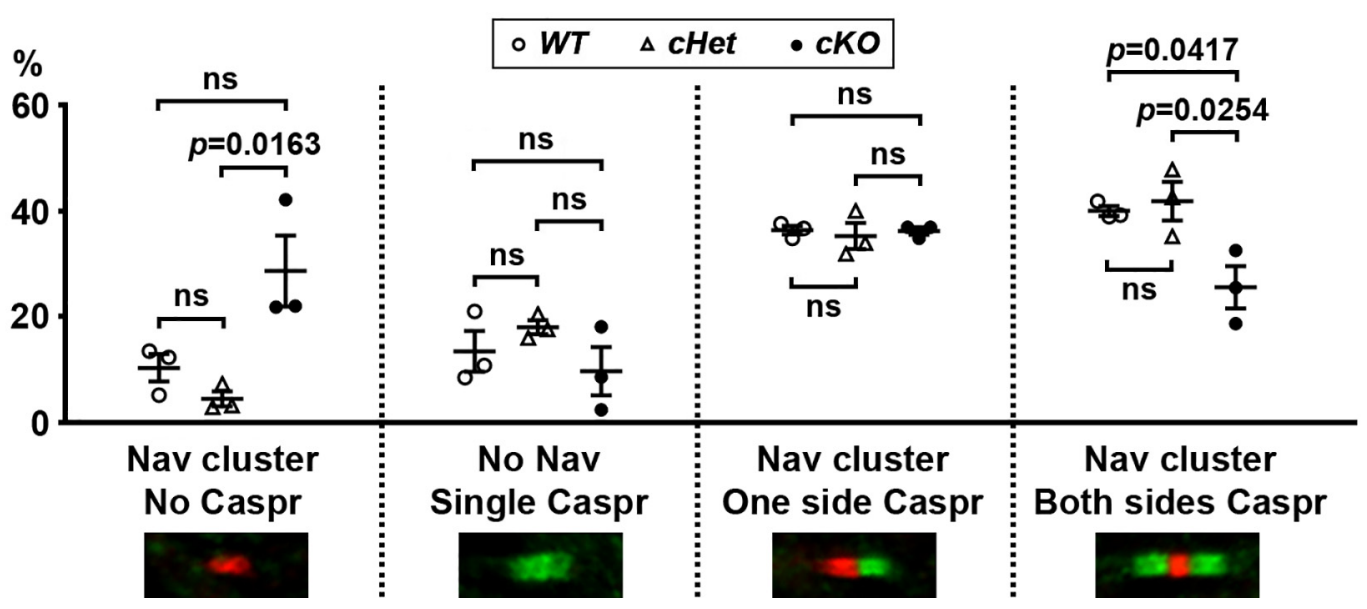

Figure 8. CNS node assembly is delayed in mice lacking oligodendrocyte $\beta \| l$ spectrin. A, Optic nerve sections immunostained for Nav channels (red) or Caspr (Green) in P13 WT and cKO optic nerves. Arrowhead indicates the Nav channel cluster without flanking Caspr labeling. Scale bars, $10 \mu \mathrm{m}$. B, Quantification of the sites labeled for Nav channels and Caspr in optic nerves from WT, Sptbn $7^{f / f}$ mice; CHet, Cnp-Cre;Sptbn $7^{f /+}$ mice; and CKO, Cnp-Cre;Sptbn $7^{f / f}$ mice at P13. N $=3$ mice in each group. In each mouse, two optic nerve sections were analyzed, and $\sim 100$ sites were observed in each section. C, Optic nerve sections immunostained for Nav channels (red) or Caspr (Green) in 14-week-old WT and cKO optic nerves. Scale bars, $10 \mu \mathrm{m}$.

nerves compared with WT or $\mathrm{cHet}$ (Fig. 9A,C). At 14 weeks of age, no significant difference of nodal gap length was observed between $W T(0.76 \pm 0.09 \mu \mathrm{m})$ and $c K O(0.95 \pm 0.06 \mu \mathrm{m})$ mice (Student's $t$ test, $p=0.1503 ; n=3$ mice in each group; $60-77$ nodal gaps were measured in each mouse). The elongation of gaps between two Caspr clusters was associated with the elongation of nodal protein clusters (Fig. 9B). In middle-aged mice, many nodal Nav channel/ $\beta \mathrm{IV}$ spectrin-labeled nodes were significantly longer $(>2 \mu \mathrm{m}$ length) in $c K O$ optic nerves than in WT or cHet mice (Fig. 9B,D). For comparison, at 14 weeks of age, long nodal Nav channel clusters ( $>2 \mu \mathrm{m}$ length) were rare, but were more frequently observed in
cKO optic nerves $(4.49 \pm 0.23 \%)$ than in WT optic nerves $(2.05 \pm$ $0.37 \%$; mean \pm SEM, $p=0.0051$, Student's $t$ test; $n=3$ mice in each group; 5 fields-of-view were analyzed in each mouse, and 219-588 nodes were observed in each field of view). An analysis of paranodal junctions in the CNS using TEM confirmed their disorganization. Specifically, we found a partial loss of paranodal transverse bands and disorganized paranodal loops in optic nerves and spinal cords from $c K O$ mice at 60 weeks of age (Fig. 9E). Finally, despite the disorganization of paranodes in middle-aged $c K O \mathrm{CNS}$, the density of nodes (i.e., nodes/field-of-view, $142.10 \times 106.48 \mu \mathrm{m}$ ) was comparable in the optic nerves at 60 weeks: $157 \pm 6.1$ in WT, $166 \pm 8.0$ 
A
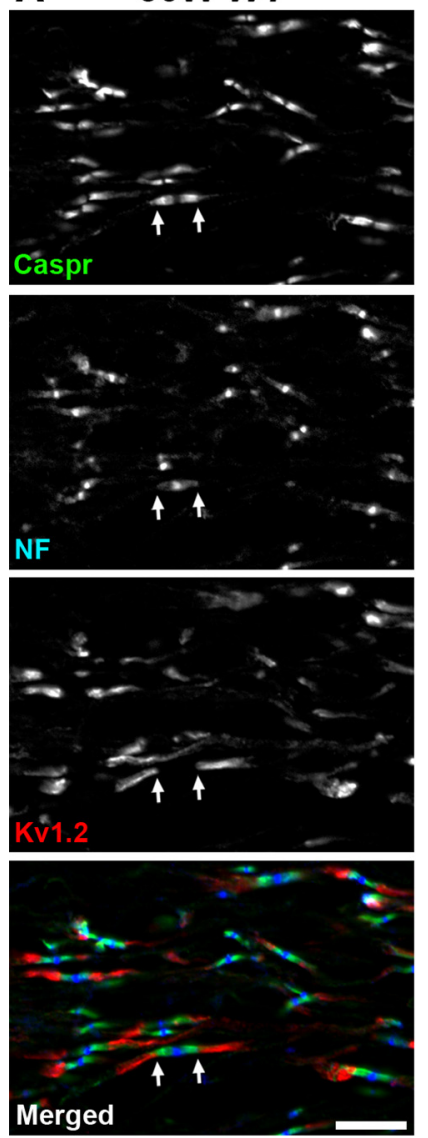

60W cKO
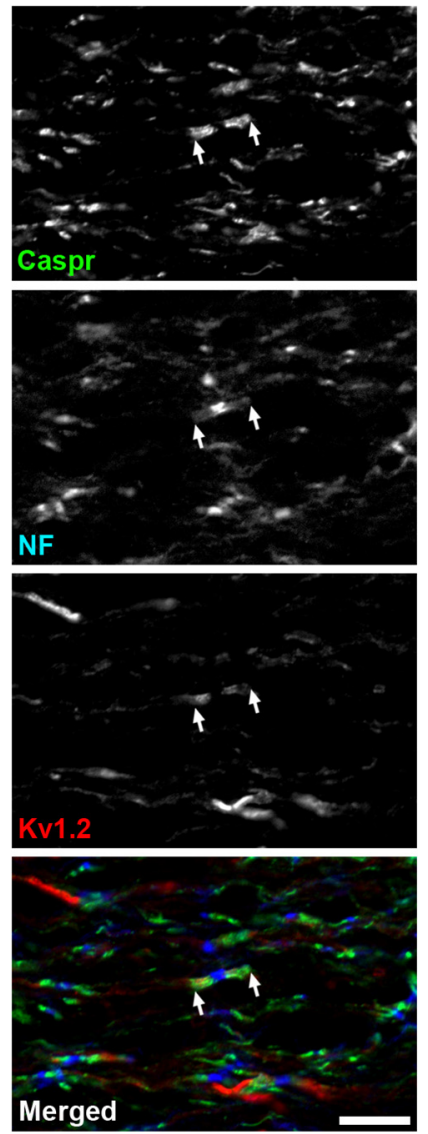

B
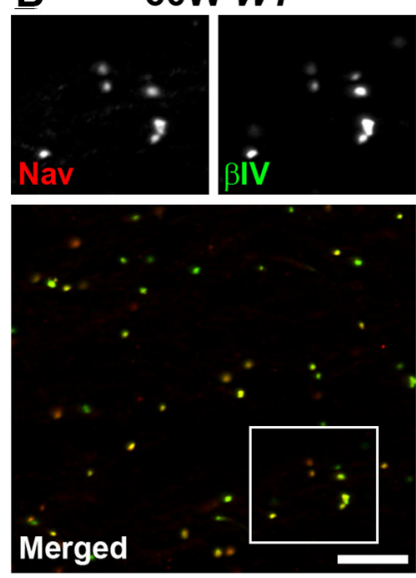

C 60 weeks optic nerves Node length $(\mu \mathrm{m})$

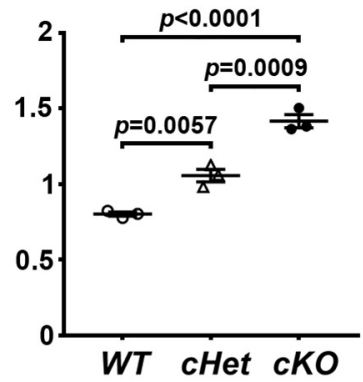

60W cKO
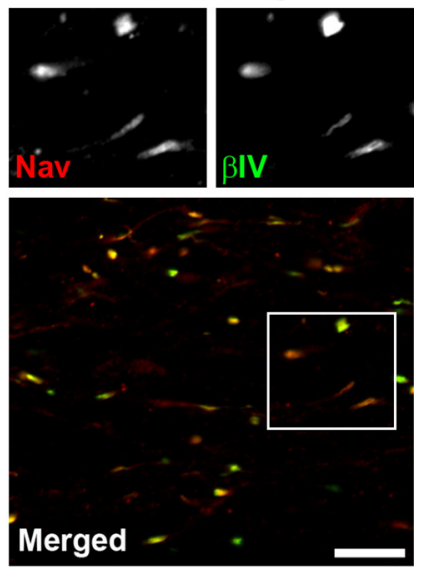

D 60 weeks optic nerves

Elongated node (\%)

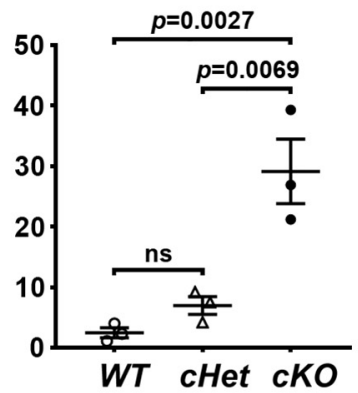

\section{E}

60W WT
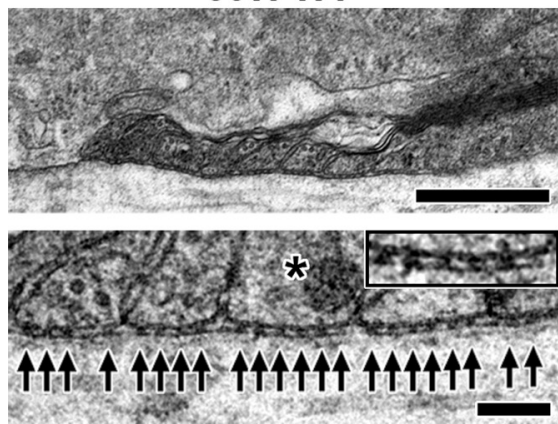

60W cKO
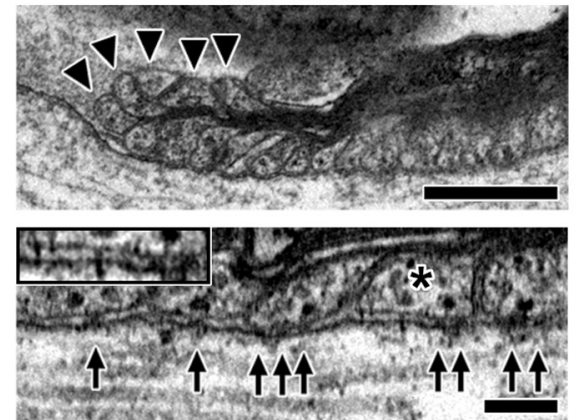

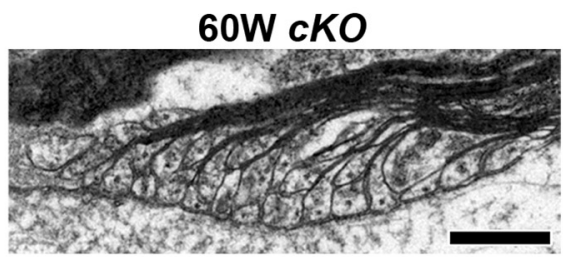

Figure 9. CNS nodes and paranodes are disrupted in middle-aged mutant mice lacking oligodendrocyte $\beta \| l$ spectrin. $A, B, 0$ ptic nerve sections from WT (Sptbn $\left.7^{f / f}\right)$ or $C K O\left(C n p-C r e ; S p t b n 7^{f / f}\right)$ mice at 60 weeks of age immunostained using antibodies against Caspr (green), NF (blue), and Kv1.2 (A, red) or Nav channels (red) and $\beta I V$ spectrin ( $\boldsymbol{B}$, green). Arrows indicate the boundary between paranodes and juxtaparanodes. $\boldsymbol{B}$, Enlarged images of the individual staining for Nav channels and $\beta \mathrm{IV}$ spectrin in boxed areas (bottom) are shown in the top. Scale bars, $10 \mu \mathrm{m}$. $\boldsymbol{C}$, Node length (distance between 2 paranodal Caspr clusters) in optic nerves at 60 weeks old. WT, Sptbn $7^{f / f}$; CHet, Cnp-Cre;Sptbn $7^{f /+}$; and CKO, Cnp-Cre;Sptbn $7^{f / f}$ mice. N $=3$ mice in each group. In each mouse, three optic nerve sections were analyzed, and 100 nodal gaps were measured in each section. $D$, Frequency of elongated nodes $(>2 \mu \mathrm{m})$ per total nodes in optic nerves at 60 weeks of age, measured by Nav channel and $\beta \mathrm{IV}$ spectrin immunostaining as shown in B.WT,Sptbn $7^{f / f} ; \mathrm{CHet}, \mathrm{Cnp}-\mathrm{Cre} ; \mathrm{Sptbn} 7^{f /+} ;$ and $\mathrm{KO}$, Cnp-Cre;Sptbn $7^{\mathrm{f} / \mathrm{f}}$ mice. $\mathrm{N}=3$ mice in each group. In each mouse, three optic nerve sections were analyzed, and 117-192 nodes were observed in each section. $E$, TEM of paranodes in $c K 0$ spinal cords at 60 weeks of age. Arrows indicate transverse bands. The insets in bottom two panels show enlarged images of axon-glial interface of paranodal lateral loops (asterisks). Arrowheads indicate abnormally inverted paranodal lateral loops (middle column). Some paranodal lateral loops lie on top of each other and do not reach the axolemma (right column). Scale bars: top three panels, $0.5 \mu \mathrm{m}$; bottom two panels, $0.1 \mu \mathrm{m}$.

in $c H e t$, and $145 \pm 12.5$ in $c K O$ (mean \pm SEM, $p=0.3401$, one-way ANOVA; $n=3$ mice in each group, 9 fields-of-view were analyzed per mouse). These findings suggest that oligodendrocyte $\beta$ II spectrin contributes to maintenance of nodal and paranodal architecture.

\section{Discussion}

Recent studies indicate that myelinating glial cells promote Nav channel clustering at nodes of Ranvier via two distinct mechanisms: (1) interaction between glia-derived ECM proteins and axonal
NF186, and (2) through paranodal axoglial junctions (Rasband and Peles, 2015). These two glia-dependent mechanisms converge on the axonal cytoskeleton, which can cluster Nav channels (Ho et al., 2014; Amor et al., 2017). Despite its importance, the composition of the glial paranode remains largely unknown. The glial paranodal cell adhesion molecule NF155 is critical for axoglial junction assembly, and thereby also regulates formation and maintenance of ion channel clustering at and near nodes (Tait et al., 2000; Pillai et al., 2009; 
Taylor et al., 2017). The absence of glial NF155 during developmental myelination causes axonal Caspr and contactin to fail to localize at the paranodes. Without these paranodal proteins transverse bands are absent and juxtaparanodal $\mathrm{K}^{+}$channels mislocalize to paranodes in both the PNS and CNS (Pillai et al., 2009). However, the loss of paranodal junctions causes only minor alterations in nodal protein clusters (Bhat et al., 2001; Boyle et al., 2001; Rios et al., 2003; Pillai et al., 2009). Remarkably, the paranodal axonal cytoskeleton assembled by these junctions has the ability to cluster Nav channels at both PNS and CNS nodes in the absence of axonal NF186 (Zonta et al., 2008; Amor et al., 2017). Ablation of glial NF155 in adult mice after completion of myelination causes loss of paranodal transverse bands and mislocalization of juxtaparanodal $\mathrm{K}^{+}$channels to paranodes (Pillai et al., 2009). However, this is not accompanied by destabilization of nodal protein clusters (Pillai et al., 2009; Taylor et al., 2017). Ablation of both axonal NF186 and glial NF155 simultaneously in mature nerves causes accelerated destabilization of the node when compared with ablation of NF186 alone, suggesting that the stability of nodal clusters is enhanced when the flanking paranodes are intact (Taylor et al., 2017). NF155 and spectrin-binding ankyrins are also found at glial paranodes: AnkyrinB in Schwann cells and AnkG in oligodendrocytes (Chang et al., 2014). Our results suggest that paranodal $\beta$ II spectrin links NF155 and ankyrins to the actin cytoskeleton in myelinating glia. Our observations in $c \mathrm{KO}$ mice suggest that glial $\beta$ II spectrin contributes to timely assembly of paranodal junctions and the stabilization of glial paranodal protein complexes in both the PNS and CNS.

During PNS development, we found altered clustering of paranodal proteins in $\beta$ II spectrin $c K O$ mice (Fig. 5). Some nodal protein clusters were also elongated or dispersed in association with the disorganized paranodes. The loss of Schwann cell $\beta$ II spectrin may alter elongation of Schwann cell processes during developmental myelination as well as paranodal junction assembly. These disorganized paranodal and nodal clusters may contribute to the conduction slowing observed in sciatic nerves and presumably the reduced grip strength in juvenile $c \mathrm{KO}$ mice (Fig. 2). However, these abnormalities were found in only some of the paranodes (mean 27.3\%; Fig. 5D) and nodes (mean 11.7\%; Fig. 5E) and these functional and structural abnormalities eventually resolved. In contrast, glial-specific ablation of NF155 using the Cnp-Cre driver line caused a more profound phenotype and nerve conduction failure, and these NF155-null mutants died at P16-P17 (Pillai et al., 2009). We speculate that the milder phenotype in $\beta I I$ spectrin $c K O$ mice may reflect partial compensation by other spectrins, as we have previously shown in axonal spectrins and ankyrins (Ho et al., 2014). Such compensatory mechanisms may also contribute to the mostly preserved myelin sheaths in $\beta$ II spectrin $c K O$ mice (Figs. $1 A, B, 3$ ), whereas knockdown of Schwann cell $\beta$ II spectrin using shRNA inhibited myelination in in vitro myelinating cocultures (Susuki et al., 2011).

Although PNS nodes and paranodes were normal in young adult $\beta \mathrm{II}$ spectrin $c K O$ mice, some paranodes were altered in the middle-aged mutants (Fig. 6). Importantly, the potential link between Schwann cell ankyrins, NF155, and $\beta$ II spectrin was consistent with the loss of NF155 and Caspr in these middle-aged cKO mice (Fig. 6). Our findings strongly suggest a role for Schwann cell $\beta$ II spectrin in the maintenance of paranodal axoglial junctions. Despite the preserved nodal and juxtaparanodal ion channel clustering in the middle-aged $c K O$ mice, paranodal abnormalities may still affect nerve conduction, as mathematical modeling has suggested that subtle paranodal detachment induces nerve conduction slowing (Babbs and Shi, 2013). Indeed, middle-aged $\beta$ II spectrin $c K O$ mice showed significant nerve conduction slowing and reduced grip strength (Fig. 2).

Similar to the PNS, we found altered nodes and paranodes during CNS development in the $\beta$ II spectrin $c K O$ mice (Fig. 8). In P13 cKO optic nerves, the frequency of nodal clusters without associated paranodes was higher than in WT controls, whereas the frequency of mature nodes and paranodes was lower (Fig. $8 B$ ), suggesting a function for oligodendrocyte $\beta$ II spectrin in CNS paranode formation. These findings are consistent with the role of NF155 for CNS paranode assembly, although NF155-null mutants still display a more profound phenotype (Zonta et al., 2008; Pillai et al., 2009). Importantly, these abnormalities during early development in $\beta$ II spectrin $c K O$ optic nerves (Fig. $8 A, B$ ) resemble the delay in CNS node and paranode assembly in a glia-specific AnkG conditional knock-out (Chang et al., 2014). AnkG expressed by myelinating oligodendrocytes is highly enriched at the glial side of paranodes and interacts with NF155 (Chang et al., 2014). The striking similarity of the phenotype in the $\beta$ II spectrin $c K O$ (Fig. $8 A, B$ ) and AnkG $c K O$ (Chang et al., 2014), and the fact that ankyrins and spectrins form functional pairs, suggests an interaction between oligodendrocyte $\beta$ II spectrin and AnkG, although it is not known whether oligodendrocyte $\beta$ II spectrin is enriched in paranodes. Similar to the PNS, the optic nerves from young adult $\beta I$ spectrin $c K O$ mice showed almost normal nodes and paranodes (Fig. $8 C$ ). However, in middle-aged mutant mice, we found elongated nodes, disorganized paranodes, and $\mathrm{K}^{+}$channel mislocalization into paranodal area in the optic nerves (Fig. 9). Similarly, ablation of glial NF155 induced in P23 mice caused mislocalization of juxtaparanodal $\mathrm{K}^{+}$channels to paranodes and loss of paranodal transverse bands in spinal cords, although Caspr immunoreactivity remained at paranodes (Pillai et al., 2009). Together, these findings strongly suggest that oligodendrocyte $\beta$ II spectrin contributes to formation and maintenance of nodes and paranodes.

In conclusion, our study demonstrates that the glial submembranous cytoskeleton formed by $\beta$ II spectrin contributes to assembly of paranodal junctions and nodes of Ranvier in both the PNS and CNS. These findings may also provide an important clue to better understand mechanisms of demyelination and neuropathy, because degradation of spectrins has been implicated in the pathophysiology of various neurological diseases and injuries, such as multiple sclerosis (Shields et al., 1999) or traumatic brain injury (Mondello et al., 2010), and disruption of nodes and paranodes has been described in these conditions (Coman et al., 2006; Howell et al., 2006; Reeves et al., 2010). We propose that defining the role of the glial cytoskeleton will provide further insights into the molecular mechanisms of formation, maintenance, disruption, and potential mechanisms for repair of myelinated nerve fibers.

\section{References}

Amor V, Feinberg K, Eshed-Eisenbach Y, Vainshtein A, Frechter S, Grumet M, Rosenbluth J, Peles E (2014) Long-term maintenance of $\mathrm{Na}+$ channels at nodes of Ranvier depends on glial contact mediated by gliomedin and NrCAM. J Neurosci 34:5089-5098. CrossRef Medline

Amor V, Zhang C, Vainshtein A, Zhang A, Zollinger DR, Eshed-Eisenbach Y, Brophy PJ, Rasband MN, Peles E (2017) The paranodal cytoskeleton clusters $\mathrm{Na}+$ channels at nodes of ranvier. eLife 6:e21392. CrossRef Medline

Babbs CF, Shi R (2013) Subtle paranodal injury slows impulse conduction in a mathematical model of myelinated axons. PLoS One 8:e67767. CrossRef Medline

Bhat MA, Rios JC, Lu Y, Garcia-Fresco GP, Ching W, St Martin M, Li J, Einheber S, Chesler M, Rosenbluth J, Salzer JL, Bellen HJ (2001) Axon-glia interactions and the domain organization of myelinated axons requires neurexin IV/Caspr/Paranodin. Neuron 30:369-383. CrossRef Medline

Boyle ME, Berglund EO, Murai KK, Weber L, Peles E, Ranscht B (2001) Contactin 
orchestrates assembly of the septate-like junctions at the paranode in myelinated peripheral nerve. Neuron 30:385-397. CrossRef Medline

Brivio V, Faivre-Sarrailh C, Peles E, Sherman DL, Brophy PJ (2017) Assembly of CNS nodes of Ranvier in myelinated nerves is promoted by the axon cytoskeleton. Curr Biol 27:1068-1073. CrossRef Medline

Chang KJ, Zollinger DR, Susuki K, Sherman DL, Makara MA, Brophy PJ, Cooper EC, Bennett V, Mohler PJ, Rasband MN (2014) Glial ankyrins facilitate paranodal axoglial junction assembly. Nat Neurosci 17:16731681. CrossRef Medline

Coman I, Aigrot MS, Seilhean D, Reynolds R, Girault JA, Zalc B, Lubetzki C (2006) Nodal, paranodal and juxtaparanodal axonal proteins during demyelination and remyelination in multiple sclerosis. Brain 129:31863195. CrossRef Medline

Desmazieres A, Zonta B, Zhang A, Wu LM, Sherman DL, Brophy PJ (2014) Differential stability of PNS and CNS nodal complexes when neuronal neurofascin is lost. J Neurosci 34:5083-5088. CrossRef Medline

Eshed Y, Feinberg K, Poliak S, Sabanay H, Sarig-Nadir O, Spiegel I, Bermingham JR Jr, Peles E (2005) Gliomedin mediates Schwann cell-axon interaction and the molecular assembly of the nodes of Ranvier. Neuron 47: 215-229. CrossRef Medline

Feinberg K, Eshed-Eisenbach Y, Frechter S, Amor V, Salomon D, Sabanay H, Dupree JL, Grumet M, Brophy PJ, Shrager P, Peles E (2010) A glial signal consisting of gliomedin and NrCAM clusters axonal $\mathrm{Na}+$ channels during the formation of nodes of Ranvier. Neuron 65:490-502. CrossRef Medline

Galiano MR, Bosc C, Schweitzer A, Andrieux A, Job D, Hallak ME (2004) Astrocytes and oligodendrocytes express different STOP protein isoforms. J Neurosci Res 78:329-337. CrossRef Medline

Galiano MR, Jha S, Ho TS, Zhang C, Ogawa Y, Chang KJ, Stankewich MC, Mohler PJ, Rasband MN (2012) A distal axonal cytoskeleton forms an intra-axonal boundary that controls axon initial segment assembly. Cell 149:1125-1139. CrossRef Medline

Garcia-Fresco GP, Sousa AD, Pillai AM, Moy SS, Crawley JN, Tessarollo L, Dupree JL, Bhat MA (2006) Disruption of axo-glial junctions causes cytoskeletal disorganization and degeneration of purkinje neuron axons. Proc Natl Acad Sci U S A 103:5137-5142. CrossRef Medline

Gopalakrishnan G, Awasthi A, Belkaid W, De Faria O Jr, Liazoghli D, Colman DR, Dhaunchak AS (2013) Lipidome and proteome map of myelin membranes. J Neurosci Res 91:321-334. CrossRef Medline

Griggs RB, Yermakov LM, Drouet DE, Nguyen DVM, Susuki K (2018) Methylglyoxal disrupts paranodal axoglial junctions via calpain activation. ASN Neuro 10:1759091418766175. CrossRef Medline

Ho TS, Zollinger DR, Chang KJ, Xu M, Cooper EC, Stankewich MC, Bennett V, Rasband MN (2014) A hierarchy of ankyrin-spectrin complexes clusters sodium channels at nodes of Ranvier. Nat Neurosci 17:1664-1672. CrossRef Medline

Howell OW, Palser A, Polito A, Melrose S, Zonta B, Scheiermann C, Vora AJ, Brophy PJ, Reynolds R (2006) Disruption of neurofascin localization reveals early changes preceding demyelination and remyelination in multiple sclerosis. Brain 129:3173-3185. CrossRef Medline

Huang CY, Zhang C, Zollinger DR, Leterrier C, Rasband MN (2017) An $\alpha \mathrm{II}$ spectrin-based cytoskeleton protects large-diameter myelinated axons from degeneration. J Neurosci 37:11323-11334. CrossRef Medline

Lappe-Siefke C, Goebbels S, Gravel M, Nicksch E, Lee J, Braun PE, Griffiths IR, Nave KA (2003) Disruption of Cnpl uncouples oligodendroglial functions in axonal support and myelination. Nat Genet 33:366-374. CrossRef Medline

Marcus J, Honigbaum S, Shroff S, Honke K, Rosenbluth J, Dupree JL (2006) Sulfatide is essential for the maintenance of CNS myelin and axon structure. Glia 53:372-381. CrossRef Medline

Mondello S, Robicsek SA, Gabrielli A, Brophy GM, Papa L, Tepas J, Robertson C, Buki A, Scharf D, Jixiang M, Akinyi L, Muller U, Wang KK, Hayes RL (2010) $\alpha$ II-Spectrin breakdown products (SBDPs): diagnosis and outcome in severe traumatic brain injury patients. J Neurotrauma 27: 1203-1213. CrossRef Medline

Nelson AD, Jenkins PM (2017) Axonal membranes and their domains: assembly and function of the axon initial segment and node of Ranvier. Front Cell Neurosci 11:136. CrossRef Medline

Ogawa Y, Schafer DP, Horresh I, Bar V, Hales K, Yang Y, Susuki K, Peles E, Stankewich MC, Rasband MN (2006) Spectrins and ankyrinB constitute a specialized paranodal cytoskeleton. J Neurosci 26:5230-5239. CrossRef Medline

Ohara R, Yamakawa H, Nakayama M, Ohara O (2000) Type II brain 4.1 (4.1B/
KIAA0987), a member of the protein 4.1 family, is localized to neuronal paranodes. Brain Res Mol Brain Res 85:41-52. CrossRef Medline

Otani Y, Yermakov LM, Dupree JL, Susuki K (2017) Chronic peripheral nerve compression disrupts paranodal axoglial junctions. Muscle Nerve 55:544-554. CrossRef Medline

Patzig J, Jahn O, Tenzer S, Wichert SP, de Monasterio-Schrader P, Rosfa S, Kuharev J, Yan K, Bormuth I, Bremer J, Aguzzi A, Orfaniotou F, Hesse D, Schwab MH, Möbius W, Nave KA, Werner HB (2011) Quantitative and integrative proteome analysis of peripheral nerve myelin identifies novel myelin proteins and candidate neuropathy loci. J Neurosci 31:1636916386. CrossRef Medline

Pillai AM, Thaxton C, Pribisko AL, Cheng JG, Dupree JL, Bhat MA (2009) Spatiotemporal ablation of myelinating glia-specific neurofascin $\left(\mathrm{Nfasc}^{\mathrm{NF155}}\right.$ ) in mice reveals gradual loss of paranodal axoglial junctions and concomitant disorganization of axonal domains. J Neurosci Res 87:1773-1793. CrossRef Medline

Rasband MN, Peles E (2015) The nodes of Ranvier: molecular assembly and maintenance. Cold Spring Harb Perspect Biol 8:a020495. CrossRef Medline

Rasband MN, Peles E, Trimmer JS, Levinson SR, Lux SE, Shrager P (1999) Dependence of nodal sodium channel clustering on paranodal axoglial contact in the developing CNS. J Neurosci 19:7516-7528. CrossRef Medline

Reeves TM, Greer JE, Vanderveer AS, Phillips LL (2010) Proteolysis of submembrane cytoskeletal proteins ankyrin-G and $\alpha$ II-spectrin following diffuse brain injury: a role in white matter vulnerability at nodes of Ranvier. Brain Pathol 20:1055-1068. CrossRef Medline

Rios JC, Rubin M, St Martin M, Downey RT, Einheber S, Rosenbluth J, Levinson SR, Bhat M, Salzer JL (2003) Paranodal interactions regulate expression of sodium channel subtypes and provide a diffusion barrier for the node of Ranvier. J Neurosci 23:7001-7011. CrossRef Medline

Schafer DP, Bansal R, Hedstrom KL, Pfeiffer SE, Rasband MN (2004) Does paranode formation and maintenance require partitioning of neurofascin 155 into lipid rafts? J Neurosci 24:3176-3185. CrossRef Medline

Shields DC, Schaecher KE, Saido TC, Banik NL (1999) A putative mechanism of demyelination in multiple sclerosis by a proteolytic enzyme, calpain. Proc Natl Acad Sci U S A 96:11486-11491. CrossRef Medline

Susuki K, Raphael AR, Ogawa Y, Stankewich MC, Peles E, Talbot WS, Rasband MN (2011) Schwann cell spectrins modulate peripheral nerve myelination. Proc Natl Acad Sci U S A 108:8009-8014. CrossRef Medline

Susuki K, Chang KJ, Zollinger DR, Liu Y, Ogawa Y, Eshed-Eisenbach Y, Dours-Zimmermann MT, Oses-Prieto JA, Burlingame AL, Seidenbecher CI, Zimmermann DR, Oohashi T, Peles E, Rasband MN (2013) Three mechanisms assemble central nervous system nodes of Ranvier. Neuron 78:469-482. CrossRef Medline

Susuki K, Otani Y, Rasband MN (2016) Submembranous cytoskeletons stabilize nodes of Ranvier. Exp Neurol 283:446-451. CrossRef Medline

Tait S, Gunn-Moore F, Collinson JM, Huang J, Lubetzki C, Pedraza L, Sherman DL, Colman DR, Brophy PJ (2000) An oligodendrocyte cell adhesion molecule at the site of assembly of the paranodal axo-glial junction. J Cell Biol 150:657-666. CrossRef Medline

Tang Y, Katuri V, Dillner A, Mishra B, Deng CX, Mishra L (2003) Disruption of transforming growth factor-beta signaling in ELF beta-spectrindeficient mice. Science 299:574-577. CrossRef Medline

Taylor AM, Saifetiarova J, Bhat MA (2017) Postnatal loss of neuronal and glial neurofascins differentially affects node of Ranvier maintenance and myelinated axon function. Front Cell Neurosci 11:11. CrossRef Medline

Voas MG, Lyons DA, Naylor SG, Arana N, Rasband MN, Talbot WS (2007) $\alpha$ II-Spectrin is essential for assembly of the nodes of Ranvier in myelinated axons. Curr Biol 17:562-568. CrossRef Medline

Zhang C, Susuki K, Zollinger DR, Dupree JL, Rasband MN (2013) Membrane domain organization of myelinated axons requires $\beta$ II spectrin. J Cell Biol 203:437-443. CrossRef Medline

Zhang Y, Chen K, Sloan SA, Bennett ML, Scholze AR, O'Keeffe S, Phatnani HP, Guarnieri P, Caneda C, Ruderisch N, Deng S, Liddelow SA, Zhang C, Daneman R, Maniatis T, Barres BA, Wu JQ (2014) An RNA-sequencing transcriptome and splicing database of glia, neurons, and vascular cells of the cerebral cortex. J Neurosci 34:11929-11947. CrossRef Medline

Zonta B, Tait S, Melrose S, Anderson H, Harroch S, Higginson J, Sherman DL, Brophy PJ (2008) Glial and neuronal isoforms of neurofascin have distinct roles in the assembly of nodes of Ranvier in the central nervous system. J Cell Biol 181:1169-1177. CrossRef Medline 